\title{
Specialized Metabolites in Floral Resources: Effects and Detection in Buff-Tailed Bumblebees
}

\begin{abstract}
Ombeline Sculfort ${ }^{1}$, Maxence Gérard ${ }^{2,3}$, Antoine Gekière $^{2}$, Denis Nonclercq ${ }^{4}$, Pascal Gerbaux ${ }^{5}$, Pierre Duez ${ }^{6}$ and Maryse Vanderplanck ${ }^{2 *}$

1 Laboratoire Écologie, Évolution, Interactions des Systèmes Amazoniens, Université de Guyane, Centre National de la Recherche Scientifique, Institut Français de Recherche pour l'Exploitation de la Mer, Cayenne, France, ${ }^{2}$ Laboratory of Zoology, Research Institute for Biosciences, University of Mons, Mons, Belgium, ${ }^{3}$ Division of Functional Morphology, Department of Zoology, Stockholm University, Stockholm, Sweden, ${ }^{4}$ Laboratory of Histology, Faculty of Medicine and Pharmacy, University of Mons, Mons, Belgium, ${ }^{5}$ Organic Synthesis and Mass Spectrometry Laboratory, Research Institute for Biosciences, University of Mons, Mons, Belgium, ${ }^{6}$ Unit of Therapeutic Chemistry and Pharmacognosy, Faculty of Medicine and Pharmacy, University of Mons, Mons, Belgium
\end{abstract}

The selection of appropriate food resources by bees is a critical aspect for the maintenance of their populations, especially in the current context of global change and pollinator decline. Wild bees have a sophisticated ability to forage selectively on specific resources, and can assess the quality of pollen using contact chemosensory perception (taste). While numerous studies have investigated the detection of pollen macronutrients in bees and their impact on bee health and reproductive success, only a few studies have described the gustatory responses of bees toward specialized metabolites. In addition, these studies mostly focused on the response to nectar and neglected pollen, which is the main food resource for both bee imagines and larvae. Whether bees have the ability to detect specialized toxic metabolites in pollen and then rapidly adapt their foraging behavior to avoid them is very little studied. In this study, we tested whether pollen specialized metabolites affect bumblebees at both the microcolony and individual levels (i.e., bioassays using supplemented pollen), and whether foragers detect these specialized metabolites and potentially display an avoidance behavior (i.e., preference tests using supplemented syrup). Bumblebees were fed with either amygdalin-, scopolamine- or sinigrin-supplemented pollen diets in ratios that mimic $50 \%, 100 \%$, and $200 \%$ of naturally occurring concentrations. We found no effect of these specialized metabolites on resource collection, reproductive success and stress response at the micro-colony level. At the individual level, bumblebees fed on 50\%-amygdalin or 50\%-scopolamine diets displayed the highest scores for damage to their digestive systems. Interestingly, during the preference tests, the solution with 50\%-scopolamine displayed a phagostimulatory activity, whereas solution with 50\%amygdalin had a deterrent effect and could trigger an active avoidance behavior in bumblebees, with a faster proboscis retraction. Our results suggest that regulation of toxin intake is not as well-established and effective as the regulation of nutrient intake in bees. Bees are therefore not equally adapted to all specialized pollen metabolites that they can come into contact with. Bumblebees. doi: 10.3389/fevo. 2021.669352 


\section{INTRODUCTION}

In the current context of global change and pollinator decline (Potts et al., 2016; Dicks et al., 2020), consumption of adequate food resources can provide bees with resilience to some environmental stressors, as recently demonstrated in bumblebees facing heat stress (Vanderplanck et al., 2019a), and in honeybees facing viral infections (Dolezal et al., 2019). The other side of the coin is that consumption of inadequate resources, even by an otherwise healthy organism, can lead to reduced survival and decreased immunity, as well as an increased susceptibility to pathogens and parasites (e.g., Alaux et al., 2010; DeGrandiHoffman et al., 2010; Di Pasquale et al., 2013; Roger et al., 2017; Vanderplanck et al., 2018). Selecting appropriate food resources is therefore a critical aspect for bees in order to maintain their populations (see Vaudo et al., 2015).

It is common knowledge that bees predominantly collect pollen to satisfy their nutritional and physiological requirements, it being essential for reproduction and for the health of imagines (Human et al., 2007; Di Pasquale et al., 2013; Cane, 2016; Cane et al., 2016), as well as for the development of their offspring (Génissel et al., 2002; Tasei and Aupinel, 2008a; Brodschneider and Crailsheim, 2010; Quezada-Euan et al., 2011). Pollen is a complex chemical mixture that contains both central (or primary) metabolites, which are vital for plant survival (e.g., proteins, amino acids and lipids; see Roulston et al., 2000; Weiner et al., 2010), and specialized (or secondary) metabolites, which play a key role in the interaction of the plant with the environment such as underpinning insect attraction or deterrence (e.g., alkaloids; see Kempf et al., 2010; Cook et al., 2013; Gosselin et al., 2013; Stegemann et al., 2018). Pollen composition is highly variable among plant species so bees face a high degree of variation in pollen quality (e.g., Roulston and Cane, 2000; Roulston et al., 2000; Weiner et al., 2010; Vaudo et al., 2015, 2020; Palmer-Young et al., 2019), with some pollen types being unsuitable for some bee species because of lack in essential nutrients, occurrence of toxic compounds or low digestibility leading to difficulties in extracting nutrients (e.g., Levin and Haydak, 1957; Praz et al., 2008b; Sedivy et al., 2011; Haider et al., 2013; Vanderplanck et al., 2014, 2018, 2020). This implies that even generalist bees cannot forage randomly on all available resources, but have to display selective foraging to increase their individual health and reproductive success.

Indeed, both social and solitary bees have been shown to forage selectively on different pollen types according to their nutritional quality. For instance, bumblebees preferentially collect pollen rich in proteins and amino acids (Rasheed and Harder, 1997; Robertson et al., 1999; Hanley et al., 2008; Kitaoka and Nieh, 2009; Leonhardt and Blüthgen, 2012). Such selective foraging on specific resources may arise from imprinting, with bees developing preference toward pollen types they fed on during their larval phase or as early imagines (e.g., Dobson and Peng, 1997; Cane and Sipes, 2006; Ruedenauer et al., 2020b). Additionally, social bee species could also rely on feedback from their nest, such as the rate of food consumption by larvae, in determining preferences (e.g., Ruedenauer et al., 2016). However, evidence is that pre-imaginal learning does not always prevail (e.g., Praz et al., 2008a), and that individual imagines can differentiate between different pollen types without relying on feedback from larvae (Ruedenauer et al., 2015). Wild bees have therefore a sophisticated ability to forage selectively on resources that allow them to achieve their nutritional optimum (Dobson and Bergström, 2000; Hanley et al., 2008; Ruedenauer et al., 2015, 2016). Such assessment of pollen quality could be done through olfactory (i.e., pollen odor; Dobson and Bergström, 2000), visual (i.e., pollen color; Lunau, 2000) or chemotactile cues (i.e., pollen taste; e.g., Pernal and Currie, 2002; Leonhardt and Blüthgen, 2012; Lunau et al., 2015; Ruedenauer et al., 2015, 2016; Muth et al., 2016), without knowing all components. Among these cues, it is more likely that bees would use smell (i.e., olfactory cues) and/or pollen taste (i.e., chemotactile cues) rather than pollen color to discriminate among food resources. Ruedenauer et al. (2015) have actually shown that bumblebees are able to differentiate between different nutrient concentrations using contact chemosensory perception, which is enabled via gustatory receptors on their antennae, mouthparts and tarsi (de Brito Sanchez, 2011). They are therefore able to regulate their nutrient intake by varying their foraging rate on different food resources. This selective foraging appears to be guided by the fat content and protein:lipid ratio of pollen rather than by the protein content alone (Vaudo et al., 2016a,b; Ruedenauer et al., 2020a). In particular, fatty acid cues appear to play a key role in fat regulation and foraging decisions in Bombus terrestris (Ruedenauer et al., 2020a). Hence, chemical composition of pollen might be involved in the selection and use of resources, at least in some bee species. However, the complete picture is lacking as studies on selective foraging have mainly focused on macronutrients (i.e., central metabolites), whereas only a few studies have described the gustatory responses of bees toward specialized metabolites in food (e.g., Ayestaran et al., 2010; Tiedeken et al., 2014). Moreover, these experiments have mainly used restrained bees (i.e., stressed individuals with non-natural feeding responses; Mommaerts et al., 2013), and have mostly considered specialized metabolites that occur only in nectar.

Despite this, there have been several reports on the presence of specialized metabolites in pollen of widespread plant species that represent important food resources for pollinators (Rivest and Forrest, 2020 and references cited). While the role of central metabolites as nutrients for pollinators is largely assumed (e.g., Hügel, 1962; Day et al., 1990; Herbert, 1992; Roulston et al., 2000), the role of specialized metabolites is still controversial (Manson et al., 2010; de Roode et al., 2013; Wright et al., 2013; Arnold et al., 2014; Hurst et al., 2014; Richardson et al., 2015; Stevenson et al., 2017; Stevenson, 2020). Originally, specialized metabolites evolved in plants as chemical defenses in response to selection imposed by herbivores and pathogens (Moore et al., 2014; Richards et al., 2015; Rivest and Forrest, 2020). Their occurrence in pollen could then play an important ecological role in plantpollinator interactions, such as by favoring pollen specialization or pollen mixing behavior in bees; Eckhardt et al., 2014; Rivest and Forrest, 2020). These biologically active metabolites could improve the health status of pollinators (e.g., Palmer-Young et al., 2017) through anti-oxidant (e.g., Aličić et al., 2014) and antimicrobial properties (e.g., Compean and Ynalvez, 2014), but they 
could also impede larval development (de Carvalho and Message, 2004; Arnold et al., 2014), induce malaise behavior (Hurst et al., 2014) and weaken the insect immune system through insecticidal properties (Baracchi et al., 2015). In some instances, specialized metabolites could even kill pollinators (Detzel and Wink, 1993; Adler, 2000; de Carvalho and Message, 2004). Consequently, it is critical that bees have the ability to detect pollen specialized metabolites, especially if they have negative impact on their health and fitness, and rapidly adapt their foraging behavior to avoid such toxic resources.

In this study, we performed a range of bioassays and behavioral experiments with freely moving workers of the bumblebee Bombus terrestris to determine (1) whether pollen specialized metabolites affect bumblebees at the micro-colony level (resource collection, reproduction and stress response) as well as at individual level (histological damage), (2) and whether bumblebees detect these specialized metabolites and potentially display an avoidance behavior. We focused on amygdalin, scopolamine and sinigrin; three nitrogen-containing metabolites synthesized by different plant families that are actively foraged upon by bumblebees (Erickson and Feeny, 1974; King, 1993; London-Shafir et al., 2003; Ares et al., 2015; Chowański et al., 2016; Sáez et al., 2020). We assume that bumblebees must be able to detect specialized metabolites (either through pre- or post-ingestive effects, or both) that are toxic for them at either the micro-colony or individual level. We further expect that bumblebees will consequently display an avoidance behavior, for instance by reducing their resource collection.

\section{MATERIALS AND METHODS}

\section{Model System}

Bombus terrestris is one of the most abundant and widespread bumblebee species of the West Palearctic. This social species is a highly polylectic bumblebee foraging on hundreds of different plant species belonging to numerous plant families (Kleijn and Raemakers, 2008; Rasmont et al., 2008; Leonhardt and Blüthgen, 2012). As a consequence, it has a very important role as a pollinator in wild and cultivated plant communities (Free, 1993; Velthuis and van Doorn, 2006). However, colonies do not show equivalent development on all pollen species (Vanderplanck et al., 2018), partly because of the occurrence of specialized metabolites. In this study, we focus on three nitrogen-containing metabolites, namely amygdalin, scopolamine and sinigrin.

Amygdalin belongs to the family of cyanogenic glycosides, which are chemical defenses characteristic of Rosaceae (Robinson, 1930; Conn, 1978). It occurs naturally at level of 1,889 ppm in pollen of Prunus dulcis Mill (London-Shafir et al., 2003). This Prunus species is one of the most economically valuable bee-pollinated crop species because of its high pollinator-dependence and high-market value (Sáez et al., 2020), bumblebees counting among the pollinators of almond crop fields (Dag et al., 2006; Marqués et al., 2019). Repeat consumption of such chemically defended pollen can be toxic to bees (Kevan and Ebert, 2005), especially if they are not able to detect the toxic substance. Upon enzymatic hydrolysis, amygdalin liberates cyanide; its toxicity may be explained by its metabolization to sulfocyanide, an inhibitor of the iodide pump.

Scopolamine belongs to the family of Solanaceae alkaloids, which display insecticidal and fungicidal properties characteristic of this plant family (Boulogne et al., 2012). It occurs naturally at level of 20,014 ppm in pollen of Brugmansia aurea Lagerh (Detzel and Wink, 1993). Plant species in the cosmopolitan family Solanaceae are among the most ecologically and economically important, particularly in terms of food production (e.g., potatoes and tomatoes), and are generally pollinated by bumblebees (i.e., buzz pollination) (King, 1993). The occurrence of such a biologically active compound could then render the pollen of Solanaceae species toxic to its pollinators, including bumblebees, which could be highly detrimental if the substance has no repellent effect. Scopolamine is a competitive antagonist of acetylcholine at muscarinic receptors (Fraenkel, 1959; Brown and Keith, 1987; Chowański et al., 2016). It was shown to bind to brain receptors and increase attacks on nestmates in honeybees (Gauthier et al., 1994; Ismail et al., 2008).

Sinigrin is one of the most widespread glucosinolates (mustard oil glycosides) occurring in many species of Brassicaceae and in a few other plant families (Erickson and Feeny, 1974; Mazumder et al., 2016). It has been detected at level of $1,892 \mathrm{ppm}$ in bee pollen of Brassica sp. (Ares et al., 2015). Brassicaceae is a widespread plant family that includes numerous species of agricultural and medicinal interest (Kissen et al., 2009). This plant family is known to be largely bee-pollinated and bumblebees are likely exposed to the potential insecticidal properties of its glucosinolates, depending on their avoidance behavior. Upon enzymatic hydrolysis, sinigrin yields allyl isothiocyanate, a volatile and highly pungent compound that acts as plant defense by deterring herbivores (Erickson and Feeny, 1974; Shields and Mitchell, 1995; Frisch et al., 2015).

\section{Bioassays \\ Pollen Diets}

How specialized metabolites can impact pollinator behavior, performance and health was investigated by the use of a control diet as well as amygdalin-, scopolamine-, and sinigrinsupplemented diets (i.e., test diets). The test diets contained chemicals mixed with the control diet in ratios that mimic $50 \%, 100 \%$, and $200 \%$ of the naturally occurring concentration (i.e., a total of nine test diets; see Supplementary Table 1 for naturally occurring concentrations). The control diet consisted of ground pollen loads with a dominance of Salix sp. mixed with inverted sugar syrup (BIOGLUC ${ }^{\circledR}$, Biobest) to obtain consistent ball-shaped candies. Salix pollen is described as an excellent resource for $B$. terrestris and is unlikely to display specialized metabolites at sublethal or lethal concentrations for bumblebees since it support their larval and colony development well (Tasei and Aupinel, 2008a; Moerman et al., 2017; Vanderplanck et al., 2018). Chromatographic analyses confirmed that amygdalin, scopolamine and sinigrin were absent from the control diet (for analytical details see London-Shafir et al., 2003; Ares et al., 2015). The test diets were prepared using commercial powders that were dissolved in aqueous ethanol solution (1:1) before addition 
to the control diet. Aqueous ethanol was selected because, even if all tested metabolites are soluble in water, it improved their solubility at the highest concentrations and allowed for not over-moisturizing the pollen candies as ethanol quickly evaporates. All treatment diets (both control and test diets) contained aqueous ethanol $(1: 1 ; 0.4 \mathrm{~mL} / \mathrm{g}$ of diet $)$ to control for potential negative effects of the solvent when assessing the added chemical treatments. Pollen loads of Salix were purchased from the company "Ruchers de Lorraine," which were sold as organic nutrition complement (i.e., free of pesticides).

\section{Experimental Design}

The experiments were conducted at the University of Mons from February 2015 to May 2016. A first run of bioassays was performed in 2015 for amygdalin (i.e., four treatments; control, 50\%-amygdalin, 100\%-amygdalin, and 200\%-amygdalin), and a second run in 2016 for scopolamine and sinigrin (i.e., seven treatments; control, 50\%-scopolamine, 100\%-scopolamine, 200\%-scopolamine, 50\%-sinigrin, 100\%-sinigrin, and 200\%sinigrin). Ten queenless $B$. terrestris micro-colonies were established for each treatment using workers from five different colonies (Biobest bvba, Westerlo, Belgium) that were equally distributed among the treatments to ensure homogeneity of origin. A total of 110 micro-colonies were then monitored for all experiments. Each micro-colony was composed of five 2-day-old workers placed in different plastic boxes $(10 \mathrm{~cm} \times 16 \mathrm{~cm} \times 16 \mathrm{~cm})$ in a dark room at $27^{\circ} \mathrm{C}$ and $76 \%$ relative humidity. The micro-colonies were fed ad libitum with sugar syrup (BIOGLUC ${ }^{\circledR}$, Biobest) and pollen candies that were freshly prepared and renewed every 2 days $(0.5 \mathrm{~g}, 1.0 \mathrm{~g}$, or $1.5 \mathrm{~g}$ depending on the age of the micro-colony) to avoid nutrient alteration and drying out during the experiment. Pollen and syrup collections were measured by weighing pollen candies and syrup container before their introduction into the micro-colony and after their removal. Ejected larvae were removed from the micro-colony; workers that died during the experiment were removed and replaced. Syrup and pollen supplies as well as micro-colonies monitoring were done in the darkroom under red light during the 35-day period following the first episode of egg laying of a worker. At the end of the experiment, workers were weighed. The total mass of workers was expressed as the sum of the weights of the five workers in each micro-colony, taking into account the time they spent in the micro-colony in case of death and replacement. The nest was then carefully dissected, and the number and mass of individuals were recorded for each brood stage.

\section{Micro-Colony Performance}

Feeding response and micro-colony development were evaluated based on: (i) composition (i.e., number of eggs, non-isolated larvae, isolated larvae, pupae, non-emerged and emerged drones) and fresh weight of offspring, (ii) larval ejection (i.e., number of larvae, alive and dead, removed from the nest by workers), (iii) pollen collection (i.e., amount of pollen consumed and stored) (fresh matter), (iv) pollen efficiency (i.e., the weight of hatched offspring divided by the total pollen collected per micro-colony), (v) syrup collection (i.e., amount of syrup consumed and stored) and (vi) pollen dilution (i.e., the total syrup collected divided by the total pollen collected per micro-colony) (parameters adapted from Tasei and Aupinel, 2008b). All weight parameters (i.e., brood weight, pollen collection, and syrup collection) were standardized by the total mass of workers in the micro-colonies to avoid potential bias from worker activities (i.e., consumption and brood care).

\section{Digestive Damage}

The general histology of the bumblebee digestive tract is described in details in Vanderplanck et al. (2020). It is composed of a cuticle-lined foregut (stomodaeum), a midgut (mesenteron) and a cuticle-lined hindgut (proctodaeum). Histological examination focused on the mesenteron, which is the principal site of digestion and absorption of both nutrients and ingested plant allelochemicals. It represents therefore the first line of defense against the absorption of specialized metabolites, with for instance the protective role of peritrophic membrane. Its epithelium also represents an important interface between the insect and its environment. It consists of discrete crypts and lies on connective tissue. Its major cell type is the columnar cells with numerous microvilli forming, at the apical pole, a brush-like border. These cells display a slightly granular cytoplasm and, at their center, a large ovoid and euchromatic nucleus (Calatayud and Rabhé, 2013; Sarwade and Bhawane, 2013).

Tissues for histological evaluation were prepared following the method described by Vanderplanck et al. (2020). For each treatment, four bumblebee individuals were randomly collected from the different micro-colonies and cold-anesthetized ( $n=4$ per treatment). Their abdomens were cut and incised to facilitate the fixation (Duboscq-Brazil fluid), dehydration and paraffin-embedding processes. Transverse serial sections of $5 \mu \mathrm{m}$ thicknesses were performed with a microtome (Reichert-Jung ${ }^{\circledR}$ 2040 microtome) with the use of a softening agent (Mollifex ${ }^{\mathrm{TM}}$ ), and placed on silane-coated glass slides. After rehydration, the sections were stained with Masson's Trichrome staining method.

A single-blind microscopic evaluation was carried out using a research optical microscope (Leitz ${ }^{\circledR}$ Orthoplan). This allowed for eliminating biases due to knowledge of treatment. The parameters evaluated for damage score were the common histopathological alterations in the digestive tract (Vanderplanck et al., 2020), namely: (i) disorganization or loos of the brushlike border, (ii) vacuolization of the epithelial cells (hydropic degeneration), (iii) interstitial edema, (iv) apoptosis, and (v) necrosis. All parameters were scored from 0 (no damage) to 5 (extensive changes), except necrosis parameter that was scored from 0 to 6 (see Supplementary Table 2 for criteria and score details). When necrosis parameter was set to at least 4 (i.e., sublethal damage), all other parameters were automatically set to the maximal value (5). Analysis was made of the damage score for each of the parameters on one hand, and of the total sum of damage scores (TDS) of the five parameters on the other hand. Thus, the TDS had a minimum possible total damage score of 0 and a maximum possible total damage score of 26 .

\section{Detection of Specialized Metabolites}

We tested the hypothesis that bumblebees can detect the specialized metabolites using preference tests following the protocol from Ma et al. (2016). For each treatment, 15 bumblebee 
individuals were randomly collected from five different colonies (i.e., three bumblebees per colony) and starved for $2-4 \mathrm{~h}$ in plastic vials (70 $\mathrm{mm}$ long, $25 \mathrm{~mm}$ inner diameter) in the rearing dark room at $27^{\circ} \mathrm{C}$ and $76 \%$ relative humidity. After this starvation period, bumblebees were transferred into a holding tube where they were able to move freely. The holding tube consisted in a modified $15 \mathrm{~mL}$ centrifuge tube fixed on a polystyrene holder as described in Ma et al. (2016). After a habituation phase of $3 \mathrm{~min}$, the trial started and was recorded with a digital Dino-lite USB microscope camera fixed $5 \mathrm{~cm}$ above the tip of the holding tube. The trial was recorded using the software Dinocapture 2.0, with a 26.7 frames. $\mathrm{sec}^{-1}$ and a $25 \times$ magnification rate. A drop of sugar syrup (BIOGLUC ${ }^{\circledR}$, Biobest) was presented to the bumblebee using a $1-\mathrm{mL}$ syringe. Individuals that did not consume the syrup within $5 \mathrm{~min}$ were discarded. For responsive individuals, test solutions were presented using a $100 \mu \mathrm{L}$ microcapillary tube connected to a pumping system to ensure the presence of a permanent droplet of test solution at the top of the micro-capillary tube (Ma et al., 2016). Test solutions were prepared by diluting the commercial powders directly in sugar syrup $(50 \%, 100 \%$, and $200 \%$ of the naturally occurring concentrations, Supplementary Table 1). The control solutions consisted of pure sugar syrup (negative control) and a $1 \mathrm{mM}$ quinine solution (positive control) that was proven to have a deterrent effect (Ma et al., 2016). A total of 165 workers (i.e., 15 workers per treatment and 11 treatments namely, negative control, positive control, 50\%-amygdalin, 100\%-amygdalin, 200\%-amygdalin, 50\%-scopolamine, 100\%-scopolamine, 200\%scopolamine, 50\%-sinigrin, 100\%-sinigrin, and 200\%-sinigrin) have been tested.

The 2-min test phase started as soon as the bumblebee's proboscis contacted the test or control solution inside the microcapillary tube. The lengths of liquid inside the micro-capillary tube were measured before and after the test phase to calculate the volume of solution consumed. The volume of solution consumed as well as the number of feeding bouts, the cumulative duration of the feeding bouts, the total duration of effective feeding (i.e., contact with test or control solution) and the duration of the first contact (i.e., before the first proboscis retraction) were used to evaluate the phagostimulatory or the deterrent activity of the compounds tested. A feeding bout was defined as a contact between the extended proboscis and the test solution for at least 5 s (French et al., 2015).

\section{Data Analysis}

All analyses were performed in $\mathrm{R}$ version 3.4 .0

(R Core Team, 2017).

\section{Micro-Colony Performance}

To test for differences in resource collection, reproduction (offspring mass; drone mass; number of individuals within each developmental stage), and stress response of bumblebees among diet treatments, we fitted general linear mixed effects models with concentrations as a fixed effect, and colony as a random factor. As the bioassays were conducted at different times with a significant difference among controls, separate models were fitted for each specialized metabolite. Pollen collection, syrup collection, pollen dilution, total offspring mass, and pollen efficiency per micro-colony were analyzed using models with a Gaussian error structure (i.e., normally distributed residuals, "lme" function, R-package "nlme"; Kuznetsova et al., 2017). Larval ejection was analyzed using a binomial model with the number of ejected larvae and the total number of living offspring produced per micro-colony as a bivariate response ("glmer" function, R-package "ImerTest"; Kuznetsova et al., 2017), with an observation-level random effect added to the model to account for overdispersion (i.e., each data point received a unique level of random effect that modeled the extra-parametric variation present in the data; Harrison, 2014). Numbers of individuals within each developmental stage per micro-colony were assessed using models with Poisson distribution for count data after checking for overdispersion ("glmer" function, R-package "lmerTest"; Kuznetsova et al., 2017). An observationlevel random effect was added to the Poisson models when data overdispersion occurred (Harrison, 2014). When a significant effect was found $(p<0.05)$, multiple pairwise comparison tests were performed using Tukey contrasts and FDR (false discovery rate) adjustment to determine how diet treatments significantly differed from each other ("glht" function, R-package "multcomp"; Hothorn et al., 2008). Besides, Pearson (data being normally distributed) and Spearman (data not being normally distributed) correlation tests were used to evaluate the statistical significance ( $p$-values) and the strength (correlation coefficients) of the correlation between pollen collection and total offspring mass for each specialized metabolite.

\section{Digestive Damage}

The ordinal method used for histological evaluation (i.e., scoring system) involved a non-normal distribution of data. Non-parametric analyses (i.e., Kruskal-Wallis test) were then considered to compare the damage score for each of the parameters (Supplementary Table 2) and the total sum of damage scores (TDS) among diet treatments (Gibson-Corley et al., 2013). When $p$-value was significant $(p<0.05)$, multiple pairwise comparisons (post hoc test) were performed ("kruskal" function, R-package "agricolae"; Mendiburu, 2020). Given the reduced sample size for this part of the study, a power analysis has been used to ensure sufficient power and reliability (power $=0.99$; "kwpower" function, R-package "MultNonParam"; Kolassa and Jankowski, 2021).

\section{Detection of Specialized Metabolites}

To test for differences in the phagostimulatory or the deterrent activity of the treatments, we fitted general linear mixed effects models (GLMM) with treatment as a fixed effect, and colony as a random factor. The volume of solution consumed, cumulative duration of the feeding bouts, total duration of effective feeding (i.e., contact with test or control solution) and duration of the first contact (i.e., before the first proboscis retraction) were analyzed using models with a Gaussian error structure after log transformation (i.e., log-normally distributed residuals, "lme" function, R-package "nlme"; Kuznetsova et al., 2017). The number of feeding bouts was assessed using models with Poisson distribution for count data after checking 
for overdispersion ("glmer" function, R-package "lmerTest"; Kuznetsova et al., 2017). When a significant effect was found $(p<0.05)$, multiple pairwise comparison tests were performed using Tukey contrasts to determine how treatments significantly differed from each other ("glht" function, R-package "multcomp"; Hothorn et al., 2008).

\section{RESULTS}

\section{Micro-Colony Performance Resource Collection}

We found no significant effect of diet treatment on the collection of pollen (amygdalin, $\chi^{2}=6.78$, df $=3, p=0.079$, Figure 1A; scopolamine, $\chi^{2}=5.69$, df $=3, p=0.128$, Figure 1B; sinigrin, $\chi^{2}=1.79$, df $=3, p=0.618$, Figure $1 \mathrm{C}$ ) or syrup (amygdalin, $\chi^{2}=4.82, \mathrm{df}=3, p=0.185$; scopolamine, $\chi^{2}=2.12$, $\mathrm{df}=3$, $p=0.549$; sinigrin, $\chi^{2}=2.19$, $\mathrm{df}=3, p=0.534$ ) (Supplementary Table 3). Whatever the added specialized metabolite and its concentration, micro-colonies fed the test diets did not differ from micro-colonies fed the control diet. Pearson and Spearman correlation coefficients highlighted that total pollen collection (Figures 1A-C) correlated with the total mass of hatched offspring (Figures 1D-F), regardless of the treatment (amygdalin, $r=0.775, p<0.001$; scopolamine, $\rho=0.584$, $p<0.001$; sinigrin, $r=0.771, p<0.001)$.

\section{Reproduction}

We found no significant effect of diet treatment on the total mass of hatched offspring (i.e., all developmental stages except eggs) produced by $B$. terrestris micro-colonies (amygdalin, $\chi^{2}=5.92, \mathrm{df}=3, p=0.116$, Figure 1D; scopolamine, $\chi^{2}=5.64$, $\mathrm{df}=3, p=0.131$, Figure 1E; sinigrin, $\chi^{2}=1.50, \mathrm{df}=3$, $p=0.683$, Figure 1F and Supplementary Table 3). All microcolonies produced eggs, non-isolated larvae, isolated larvae (preand post-defecating stages), pupae and non-emerged drones. We found no significant effects of treatment on numbers of individuals within each developmental stage per micro-colony $(p>0.05)$ except for the number of post-defecating larvae in the scopolamine bioassays $\left(\chi^{2}=11.31\right.$, $\left.\mathrm{df}=3, p=0.010\right)$, with post hoc Tukey analyses showing that micro-colonies fed the scopolamine diets at $100 \%$ and $200 \%$ of the naturally occurring concentration produced less post-defecating larvae than micro-colonies fed control diet (Supplementary Table 3). We then assessed if the diet treatment affected the ability of a micro-colony rearing their offspring to adulthood but found no significant difference in the number of emerged drones (amygdalin, $\chi^{2}=4.63, \mathrm{df}=3, p=0.201$; scopolamine, $\chi^{2}=6.07$, $\mathrm{df}=3, p=0.108$; sinigrin, $\chi^{2}=6.72$, $\mathrm{df}=3, p=0.081$ ) (Supplementary Table 3).

\section{Stress Response}

In response to a diet stress, adult bumblebees may display peculiar behavior such as pollen dilution (Vanderplanck et al., 2018) or larval ejection from the brood (Tasei and Aupinel, 2008a). We found no significant effect of diet treatment either on the proportion of ejected larvae in micro-colonies (amygdalin, $\chi^{2}=3.19, \mathrm{df}=3, p=0.363$, Figure 1G; scopolamine, $\chi^{2}=0.91$, $\mathrm{df}=3, p=0.822$, Figure $1 \mathrm{H}$; sinigrin, $\chi^{2}=6.30, \mathrm{df}=3$, $p=0.098$, Figure 1I) or on pollen dilution (amygdalin, $\chi^{2}=7.55$, $\mathrm{df}=3, p=0.056$; scopolamine, $\chi^{2}=3.77, \mathrm{df}=3, p=0.287$; sinigrin, $\chi^{2}=2.30, \mathrm{df}=3, p=0.513$ ) (Supplementary Table 3). Another evaluated stress response was pollen diet efficiency that highlights when a micro-colony needs to consume more pollen to produce offspring, which could then be indicative of digestibility constraint or nutrient deficiency. We found no significant effect of treatment on pollen diet efficiency (amygdalin, $\chi^{2}=0.10$, $\mathrm{df}=3, p=0.991$; scopolamine, $\chi^{2}=0.74$, $\mathrm{df}=3, p=0.864$; sinigrin, $\chi^{2}=0.83$, $\mathrm{df}=3, p=0.844$ ), with micro-colonies fed the test diets having similar pollen efficiency than microcolonies in control treatments (Supplementary Table 3). Such absence of significant difference in pollen diet efficiency was not surprising since total pollen collection (Figures 1A-C) correlated with the total mass of hatched offspring (Figures 1D-F) in our experiment, regardless of the treatment.

\section{Digestive Damage}

As expected, the control treatment did not cause damage to the digestive tract (Supplementary Table 4). The mesenteric epithelium displayed a normal organization, and the morphology of digestive cells appeared to be normal without cytoplasmic vacuolization or pyknotic nucleus. The nuclei had a smooth and regular appearance, and microvilli at the apex of the digestive cells were well-developed, without any partial degradation. No necrotic cells were observed both in the base and at the apex of the intestinal crypts that remained well shaped. Median scores of any histological criteria did not exceed 2 and the median TDS was 7.5 (Figure 2 and Supplementary Table 4).

In comparison, the 50\%-amygdalin and 50\%-scopolamine treatments had a significantly higher damage score $\left(\chi^{2}=24.02\right.$, $\mathrm{df}=9, p=0.004)$, median TDS being 25 for $50 \%$-amygdalin treatment and 24.5 for $50 \%$-scopolamine treatment (Figure 2 and Supplementary Table 4). Both treatments induced marked higher histopathological alterations in the digestive tract compared to the control, with a significant augmentation of features of apoptosis (criterion 4$)\left(\chi^{2}=26.20\right.$, $\mathrm{df}=9, p=0.002$; Supplementary Table 4) as well as of necrosis (criterion 5) for $50 \%$-amygdalin $\left(\chi^{2}=24.04\right.$, df $=9, p=0.004$; Supplementary Table 4). Pyknotic nuclei were more numerous and several necrotic cells detached from the epithelium, forming large clusters in the mesenteron lumen. Cytoplasmic vacuolization (criterion 2) was also significantly more marked for both treatments $\left(\chi^{2}=23.79\right.$, df $=9, p=0.005$; Supplementary Table 4), with hydropic degeneration in more than $50 \%$ of villus intestinal epithelial cells. Disorganization or loss of the brushlike border (criterion 1) were also more frequently observed ( $\chi^{2}=23.42, \mathrm{df}=9, p=0.005$; Supplementary Table 4 ) as well as interstitial edema (criterion 3 ) in the connective tissue that forms the central axes of intestinal crypts $\left(\chi^{2}=17.90, \mathrm{df}=9, p=0.036\right.$; Supplementary Table 4).

Damage to the digestive tract of bees exposed to the $100 \%$ amygdalin treatment were less severe but significantly higher than in the control treatment $\left(\chi^{2}=24.02, \mathrm{df}=9, p=0.004\right)$, TDS 

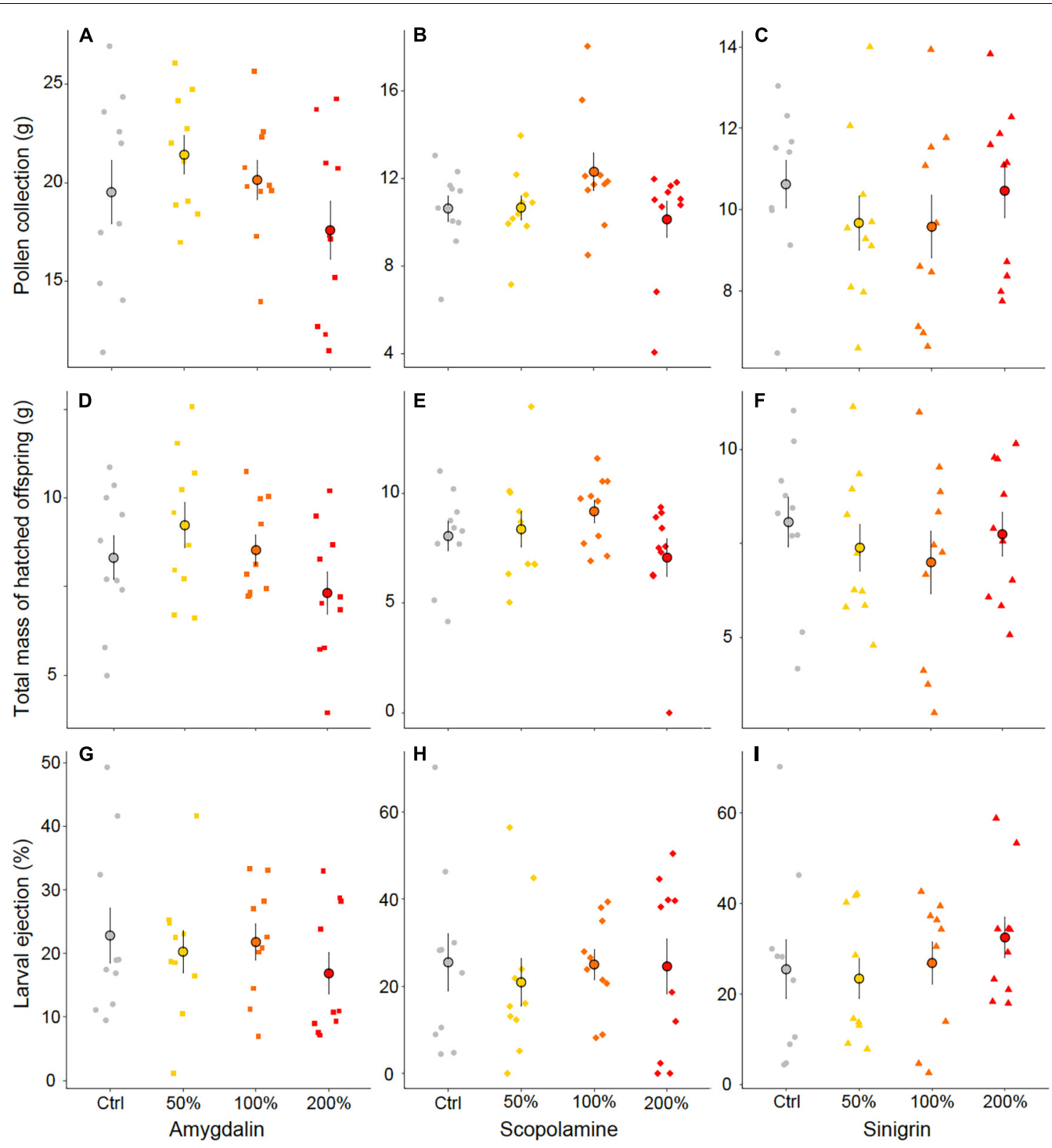

FIGURE 1 | Effects of diet treatments on resource collection, reproduction and stress response of B. terrestris in micro-colonies. (A-C) Pollen collection in each micro-colony across treatments. (D-F) Total mass of hatched offspring in each micro-colony across treatments. (G-I) Percentage of ejected larvae in each micro-colony across treatments. Each small data point represents a micro-colony and large points are mean values of each treatment. Error bars indicate the standard error of means. No significant effect was found on any parameter.

being 19.5 (Figure 2 and Supplementary Table 4). The intestinal crypts were still well-organized without interstitial edema. However, occurrence of pyknotic nuclei was significantly higher than for control treatment although we did not observe hydropic degeneration despite cytoplasmic vacuolization $\left(\chi^{2}=23.79\right.$, df $=9, p=0.005$; Supplementary Table 4). Disorganization or loss of the brush-like border was observed in $25-50 \%$ of villus intestinal epithelial cells, which is significantly higher than in control treatment $\left(\chi^{2}=23.42\right.$, df $=9, p=0.005$; Supplementary Table 4).

No degeneration of epithelial cells was observed in the digestive tract of bees exposed to the other treatments, which displayed a TDS similar to the control (Figure 2 and Supplementary Table 4). The mesenteron displayed a normal morphology as in the control treatment: the intestinal crypts were well-formed with a homogeneous brush-like border. Only some cells detached at the apex of the intestinal crypts in $100 \%$ sinigrin and $200 \%$-amygdalin treatments, which is probably due to normal cell renewal.

\section{Detection of Specialized Metabolites}

The treatments had a significant effect on the total volume of solution consumed $\left(\chi^{2}=30.42\right.$, df $\left.=10, p<0.001\right)$, whereby the consumption of quinine solution (positive control) was reduced in comparison to pure syrup solution (negative control) (Figure 3A and Supplementary Table 5). As expected, quinine displayed a deterrent activity in our assays based on food consumption. Bumblebees collected significantly more solution 


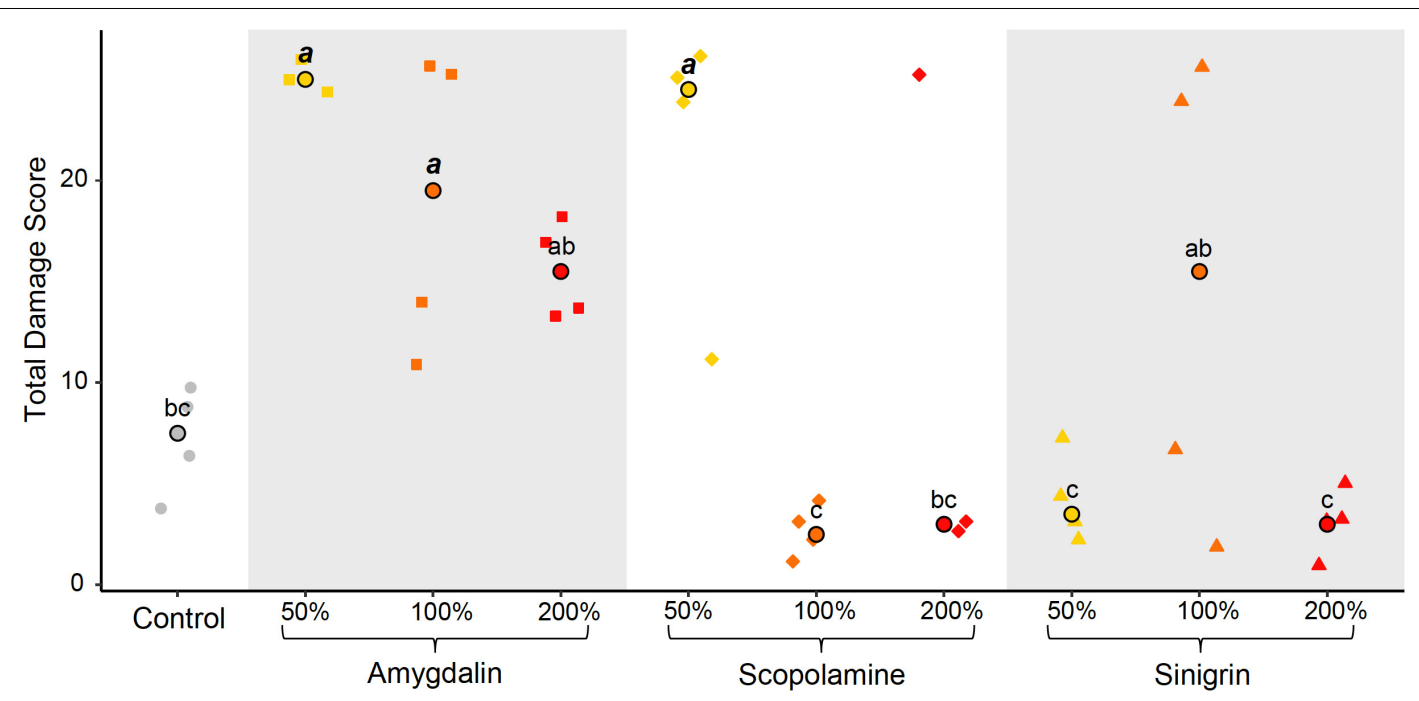

FIGURE 2 | Individual and median total damage scores. The dot-plot shows the total damage scores obtained in 38 individual tissue samples from the ten different diet treatments. Different letters indicate significant differences $(p<0.05)$ between diet treatments. Scores significantly higher than control are depicted in bold italic.

with scopolamine (50, 100, and 200\%) and 200\%-amygdalin than quinine solution, while they collected significantly less solution with 50\%-sinigrin, 50\%-amygdalin, and 200\%-sinigrin than pure syrup solution (Figure $\mathbf{3 A}$ and Supplementary Table 5). These results suggest that solutions with scopolamine $(50,100$, and $200 \%$ ) and 200\%-amygdalin displayed a phagostimulatory activity for bumblebees, whereas solutions with 50\%-sinigrin, 50\%-amygdalin, and 200\%-sinigrin had a deterrent effect. The consumption of solution with $100 \%$-sinigrin and $100 \%$ amygdalin did not differ from any controls, suggesting neither phagostimulatory nor deterrent effects.

Similarly, the treatments had a significant effect on the duration of the first contact of proboscis with the solution $\left(\chi^{2}=57.64, \mathrm{df}=10, p<0.001\right)$. The duration of the first contact with quinine solution (positive control) was significantly reduced in comparison to pure syrup solution (negative control) (Figure 3B and Supplementary Table 5), suggesting that quinine triggered an active avoidance behavior in bumblebees with a faster proboscis retraction. While the duration of the first contact with solutions containing 200\%-amygdalin, $100 \%$-sinigrin, and scopolamine (50, 100, and 200\%) was significantly longer in comparison to quinine solution (positive control) (i.e., phagostimulatory activity of test solutions), it was significantly reduced with the solutions containing $100 \%$ amygdalin, 50\%-amygdalin, and 50\%-sinigrin in comparison to pure syrup solution (negative control) (i.e., deterrent activity of test solutions) (Figure 3B and Supplementary Table 5). Only the duration of the first contact with the $200 \%$-sinigrin solution did not differ from any controls.

Likewise, the treatments had a significant effect on the cumulative duration of feeding bouts $\left(\chi^{2}=74.38\right.$, $\mathrm{df}=10$, $p<0.001)$. As expected, the cumulative duration of feeding bouts with quinine solution (positive control) was significantly reduced in comparison to pure syrup solution (negative control) (Supplementary Table 5). Post hoc Tukey test showed that the cumulative duration of feeding bouts with all test solutions (i.e., amygdalin, scopolamine and sinigrin) was significantly longer than with the quinine solution and similar to the pure sugar syrup solution (i.e., no deterrent effect based on this parameter, Supplementary Table 5). The treatments had also a significant effect on the total duration of effective feeding $\left(\chi^{2}=86.77\right.$, $\mathrm{df}=10, p<0.001$ ), whereby the total duration of effective feeding with quinine solution (positive control) was significantly reduced in comparison to pure syrup solution (negative control). For all test solutions (i.e., amygdalin, scopolamine and sinigrin), the total duration of effective feeding was significantly longer than with the quinine solution and similar to the pure sugar syrup solution (i.e., no deterrent effect based on this parameter, Supplementary Table 5). Only bumblebees in contact with the solution containing 50\%-sinigrin spent significantly less time for effective feeding than the negative control but significantly more than the positive one (Supplementary Table 5).

The treatments had also a significant effect on the frequency of feeding bouts $\left(\chi^{2}=91.63\right.$, df $\left.=10, p<0.001\right)$, whereby the number of bouts with test solutions containing scopolamine was significantly higher in comparison to other treatments. However, the number of bouts to feed the negative control did not significantly differ from the positive one, suggesting that this parameter was not the most suitable to assess the deterrent effects of substances in such assay (Supplementary Table 5).

\section{DISCUSSION}

Because floral visitors of a given plant species vary in their contribution to plant pollination (Thomson and Thomson, 1992), plants have evolved several mechanisms through which they filter their pollinators (Westerkamp and Claben-Bockhoff, 2007). Such "filtering" mechanisms allow for interactions with the most efficient 


\section{A Volume of solution consumed}

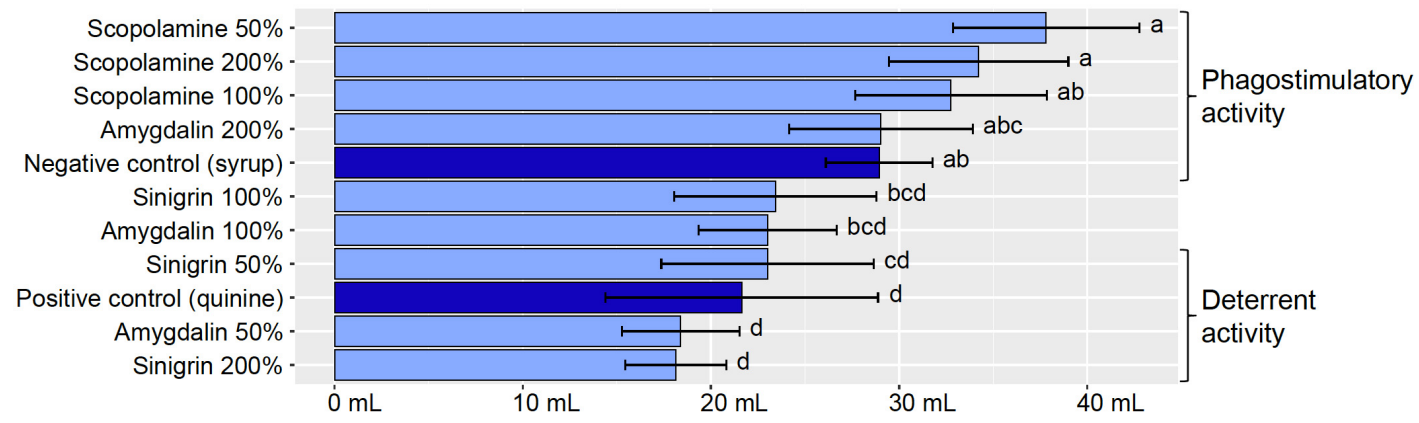

B Duration of the first contact

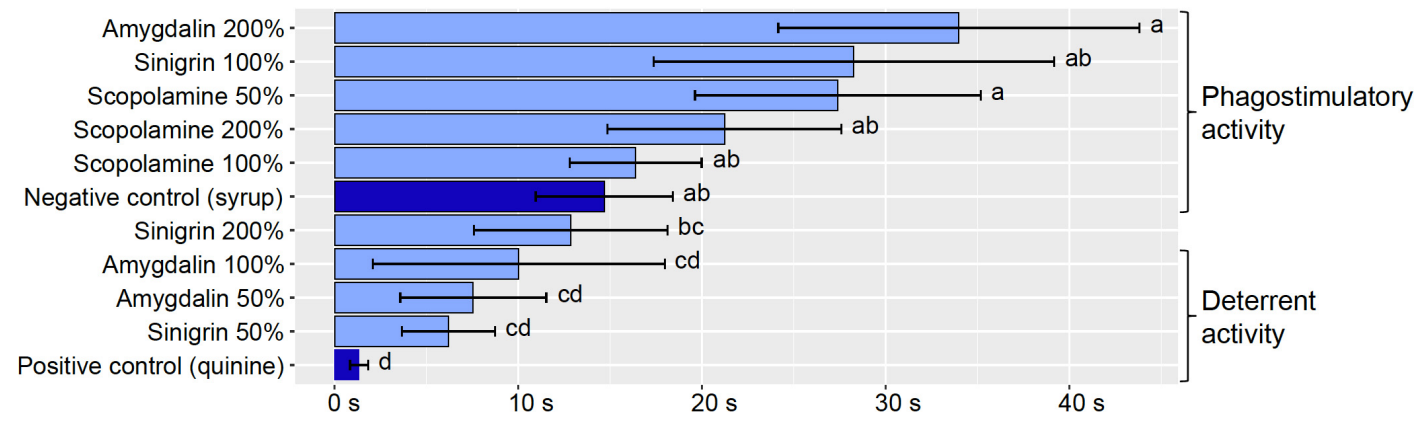

FIGURE 3 | Phagostimulatory or deterrent activity of the specialized metabolites. (A) Volume of solution consumed, and (B) duration of the first contact with the solution during preference experiments. Different letters indicate significant differences $(p<0.05)$ between treatments. Controls are depicted in dark blue, all test solutions are depicted in light blue.

pollinators to be maximized, while minimizing pollen loss due to excessive harvesting by pollen-feeding visitors (Müller, 1996). In the absence of specialized flower morphology, such "filtering" may occur through chemical properties of pollen, for instance occurrence of specialized metabolites that render the resource unsuitable to some bee species (i.e., fitness loss caused by pollen consumption) (Praz et al., 2008b; Trunz et al., 2020; Vanderplanck et al., 2020). In order to be an effective defense mechanism, these specialized metabolites have compulsorily to generate an avoidance behavior in bees (i.e., floral visits without pollen consumption), which then ensures the availability of pollen for plant reproduction. Such avoidance behavior by bees may have different mechanistic origins that are either preingestive, post-ingestive, or both. Although both mechanisms involve the sensory system of pollinators, the former results from signal detection (i.e., olfactory and chemotactile cues) without consuming the resource, while the latter results from an association between such signal and the malaise induced by resource consumption, and hence ingestion of specialized metabolites (Wright et al., 2010). Pre-ingestive detection is therefore less costly for both bees and plants, as it does not impair their reproductive success or their physiological state. Such deterrent and toxic effects of specialized metabolites from floral resources have largely been assessed in honeybees, with a bias toward nectar specialized metabolites (Detzel and Wink, 1993; Wink, 1993). Besides, studies on pollen specialized metabolites and on other bee species, including the common buff-tailed bumblebee species Bombus terrestris, remain scarce, which does not allow for a complete picture of the ecological role of specialized metabolites. One main aspect that needs to be solved is the ability of generalist pollinators to detect pollen specialized metabolites and avoid them in case of deleterious effects. Here we have assessed the ability of workers of $B$. terrestris to avoid specialized metabolites naturally occurring in pollen by distinguishing (i) post-ingestive effects at both micro-colony (i.e., resource collection, reproduction success and stress response) and individual (i.e., digestive damage) levels, as well as (ii) preingestive effects at both micro-colony (i.e., resource collection) and individual levels (i.e., detection of specialized metabolites through preference tests). As this study is one of the first to address these aspects in bumblebees, we critically discuss its limitations and suggest some parameters that would be of great interest when assessing the effects of pollen specialized metabolites (i.e., comprehensive evaluation). Caution has also to be paid regarding the significance of our results as some of the tested concentrations (i.e., 50\%- and 200\% treatments) may fall outside the natural concentration ranges encountered in plant pollen.

Considering the post-ingestive effects assessed at the microcolony level, neither resource collection, reproduction nor stress response of the micro-colonies were affected by any of the tested specialized metabolites, whatever their concentration. However, caution has to be paid regarding the interpretation of postingestive effect based on the total resource collection, as any potential adjustment of resource collection (e.g., regulation of pollen intake following brood feedback or worker malaise) 
during the experiment could have been obscured by behavioral changes. For example, micro-colonies that may have had high pollen consumption at the beginning of the experiment but which may have decreased consumption following post-ingestive regulation would display the same total pollen collection as micro-colonies that may have had low pollen consumption at the beginning of the experiment but could have increased it during colony development. A more specific analysis of pollen collection over time may have highlighted changes in resource collection during the experiment, which would have been able to better capture post-ingestive effects than the total pollen collection metric (Brochu et al., 2020; Vanderplanck et al., 2020). Moreover, total pollen collection alone does not allow for clearly distinguishing post-ingestive regulation of pollen intake from pre-ingestive regulation. Again, an analysis of pollen collection over time would allow for untangling these effects. Regarding syrup collection, no difference was detected between the supplementation and control treatments, indicating that workers did not increase their syrup intake when fed pollen supplemented with specialized metabolites. Hence occurrence of the tested specialized metabolites did not appear to affect worker resource collection (i.e., both pollen and syrup). In the same way, both reproduction and stress response of microcolonies were not impacted during the supplementation assays. Specifically, brood development and individual mass within each developmental stage were similar between micro-colonies fed with the control and the pollen supplemented with specialized metabolites. Likewise, no mitigation of unsuitable chemical properties was achieved through pollen mixing behavior during our experiment (i.e., "toxin" dilution by excessive syrup addition; Vanderplanck et al., 2018), and larval ejection was similar among micro-colonies, regardless of the treatment.

While no post-ingestive effects were detected at the microcolony level, some post-ingestive deleterious effects were clearly observed at the individual level through histological evaluation. Whereas digestive damage (i.e., quantified by the TDS) was significantly higher for workers exposed to the 50\%- amygdalin, $100 \%$ - amygdalin and 50\%-scopolamine treatments compared to those from the control treatment, no sinigrin treatments induced digestive damage. Astonishingly, the smallest concentrations triggered the most severe damage since no damage was observed in the $200 \%$ treatments, regardless of the specialized metabolite tested. Such absence of digestive damage at very high concentrations might be due to an activation of the complex machinery of endogenous immune defenses, which could occur only above a certain threshold. Indeed, as such endogenous defenses are energetically costly (Moret and Schmid-Hempel, 2000), they are likely to be activated only when the fitness loss caused by specialized metabolites is higher than the cost associated with the use of such endogenous defenses (i.e., a trade-off between the cost of endogenous defenses and the fitness loss caused by stressors; Janashia and Alaux, 2016). Besides digestive damage, evaluation of post-ingestive deleterious effects at the individual level might also be assessed through other parameters. Indeed, specialized metabolites could also affect the health status of bees, either directly by impacting their immune system (insecticidal properties) or indirectly by affecting their gut microbiota (anti-microbial properties). As in numerous organisms, bacterial symbiont communities have a substantial impact on bee physiology and ecology (Feldhaar, 2011; Engel and Moran, 2013; Bonilla-Rosso and Engel, 2018). For instance, they are involved in detoxification, protection against pathogens, digestion of food components, and activation of host immunity. Although the microbiota could provide bee host with resistance to cope with toxic metabolites (e.g., degradation; Kešnerová et al., 2017), its functional roles could be disrupted (i.e., dysbiosis) by the ingestion of naturally occurring metabolites displaying anti-microbial activities, as already shown for pesticides (Paris et al., 2020). Indeed, in the same way that pollen nutrients can modulate the bacterial composition in the bumblebee gut (Billiet et al., 2015), specialized metabolites in pollen could induce significant changes in the gut microbiota that indirectly affect bee health. Besides, direct effects of specialized metabolites on bee individual immunity might also be assessed by measuring parameters related to immunocompetence (defined as the capacity to mount an immune response), such as hemocyte concentration, fat body content, and gut melanization (Alaux et al., 2010; Roger et al., 2017; Brochu et al., 2020). Specifically, hemocytes are involved in the encapsulation of parasite followed by the melanization process (cellular immunocompetence), while the fat body is the main tissue involved in the synthesis of immunoproteins (humoral immunocompetence) (Alaux et al., 2010). Such assessment of the baseline immunocompetence could also allow for testing the hypothesis of the activation threshold of the endogenous immune defenses. The impacts of pollen specialized metabolites on the bee gut microbiota and immunity should therefore also be taken into consideration when investigating their post-ingestive effects at individual level.

Considering the pre-ingestive effects assessed at the microcolony level, total resource collection did not differ between the treatments and the control, indicating that workers did not avoid to collect pollen supplemented with specialized metabolites based on olfactory and chemotactile cues. However, preference tests showed that workers seemed able to detect these specialized metabolites through pre-ingestive mechanisms. Caution has nevertheless to be paid when comparing these two experiments since specialized metabolites were mixed within willow pollen for assessing pre-ingestive effects at the micro-colony level (i.e., bioassays), whereas they were mixed within sugar syrup for assessing pre-ingestive effects at the individual level (i.e., preference tests). This might account for the contrasting results obtained, as bees may perceive compounds in nectar but not in pollen, likely due to the higher chemical complexity of pollen (Ruedenauer et al., 2015, 2020a). Further bioassays with addition of specialized metabolites within nectar would allow for highlighting any significant effect on nectar intake at the microcolony level, annihilating the matrix effect of pollen. Regarding the preference tests, the effects depended on the tested specialized metabolite and its concentration (i.e., pre-ingestive effects at individual level). While scopolamine at all tested concentrations, amygdalin at $200 \%$, and sinigrin at $100 \%$ appeared to elicit phagostimulatory responses; amygdalin at 50 and 100\%, as well as sinigrin at 50 and $200 \%$ rather appeared to induce deterrent effects based on the volume of solution consumed or the duration 
of the first contact with the solution. The fact that scopolamine at $50 \%$ can be phagostimulatory despite its induced digestive damage is not so aberrant. For instance, it has been shown that glucosinolates may be feeding cues for the fly Scaptomyza nigrita despite their deterrent and defensive properties (Humphrey et al., 2016). The phagostimulatory activity of scopolamine remains, however, quite unexpected regarding the results of a previous study that found a deterrent effect of this specialized metabolite toward honeybees (Detzel and Wink, 1993). Such discrepancy could be explained by the different concentrations used in both studies on one hand (minimum 10,007 ppm herein; maximum $300 \mathrm{ppm}$ in Detzel and Wink, 1993), and by the different bee models used on the other hand (Bombus terrestris herein; Apis mellifera in Detzel and Wink, 1993). The possibility for different responses to the same metabolite between both bee models is supported by the finding that a same sterol, beta-sitosterol, is known to have antifeedant effects on A. mellifera whereas it is freely consumed by $B$. terrestris (Rasmont et al., 2005). Besides, the hypothesis of concentration effect is directly supported by our results since amygdalin had a phagostimulatory effect at $200 \%$, and a deterrent effect at both 50 and $100 \%$. In the same way, a concentration effect was detected for sinigrin since workers displayed a deterrent response for the $50 \%$ and $200 \%$ solutions, and a phagostimulatory response for the $100 \%$ solution. This suggests that while a given specialized metabolite may have a deterrent effect at some concentrations, it can turn out to have a phagostimulatory activity once a certain concentration threshold or range is reached. Likewise, Burden et al. (2019) found compound- and concentration-dependent responses, at both preand post-ingestive levels, in honeybees exposed to distinct heavy metals. Actually, if we confronted results from several studies, it clearly appears that concentration effects may occur, which renders impossible any extrapolation of previous studies led in different experimental conditions. For instance, Tiedeken et al. (2014) demonstrated that $B$. terrestris suffered from amygdalin deterrent effect when its concentration was at least $450 \mathrm{ppm}$. Similarly, London-Shafir et al. (2003) showed that A. mellifera reduced its consumption when amygdalin concentration was at $500 \mathrm{ppm}$ whereas the honeybees were not sensitive to amygdalin concentration of $50 \mathrm{ppm}$ (Singaravelan et al., 2005). Such findings that not only the nature of the specialized metabolite but also its concentration may influence bee foraging decisions (and hence fitness), and that these effects are likely to depend on the bee species, are particularly relevant in the current context of bee decline. Indeed, among the main drivers of bee decline, pollinators must cope with land-use changes that lead to crop homogenization and monotonous diet (Ricketts et al., 2008; Winfree et al., 2009; Goulson et al., 2015). Bees are then probably exposed to either very small quantities of specialized metabolites (if a particular resource is scarce) or substantial quantities (if a resource is abundant). In both cases, the reduction in the diversity of available floral resources is likely to prevent bees from displaying pollen mixing behavior to balance their diet and regulate their intake of specialized metabolites, regardless of their ability to detect them (see Eckhardt et al., 2014).

It is important to underline that although phagostimulatory and deterrent effects have been highlighted during the preference tests, no difference in total resource collection has been observed during the bioassays. Such contradictory results between the two experiments may arise from the co-occurrence of preand post-ingestive mechanisms during the bioassays, whereas only pre-ingestive mechanisms can occur during the preference tests. Indeed, post-ingestive mechanisms are enabled (1) by the possibility for brood feedback in the bioassays while preference tests only included one individual without any brood (Ruedenauer et al., 2016), and (2) by the possibility for conditional taste aversion in the bioassays (35 days) while preference tests comprise short feedings trials $(2 \mathrm{~min})$ that are too short for such learning to occur (Reilly and Schachtman, 2009; Wright et al., 2010). Therefore, an initial phagostimulatory response to a given specialized metabolite might be hidden during the long-time bioassays after negative brood feedback or associative learning in workers (Ruedenauer et al., 2016, 2020a), which was not necessarily reflected by the microcolony performance nor any of the measured parameters. In the same way, although an initial avoidance response to a given specialized metabolite may have occurred, workers might have increased their resource intake over a long-time period after brood feedback (nutritional requirements) or associative learning in workers (no physiological damage associated with the deterrence). Moreover, specialized metabolites were presented differently to the bumblebees according to the experiments, as above-mentioned: they were mixed within willow pollen during the bioassays whereas they were mixed within sugar syrup during the preference tests. While the co-occurrence with pollen nutrients may have allowed for their intake for nutritional purpose, when they were dissolved in sugar syrup this may have facilitated their perception by the gustatory sensilla on the mouthparts of bumblebees (de Brito Sanchez, 2011). Besides, some specialized metabolites are considered to enhance feeding only in the presence of other phagostimulants such as sucrose, which may account for the differences observed between our experiments (Nayar and Thorsteinson, 1963; Shields and Mitchell, 1995; Mazumder et al., 2016). The presence of a given specialized metabolite at a given concentration in nectar or in pollen may then influence the detection ability of bees, as well as their foraging decision. This hypothesis is strengthened by the ecological "raison d'etre" of specialized metabolites from the plant perspective: while a phagostimulatory activity of nectar through the occurrence of specialized metabolites might attract more specialized pollinators and subsequently enhance the plant fitness, a phagostimulatory activity of pollen would have a reverse effect by compromising the plant's reproductive success (e.g., Gosselin et al., 2013; Trunz et al., 2020). This highlights the importance for investigating not only the nectar specialized metabolites but also the pollen ones using appropriate and biologically relevant experimental designs. For instance, some of the metabolites, such as sinigrin and amygdalin tested herein, need specialized enzymatic activation by plant cytoplasmic enzymes, which come into contact with their substrate upon cell disruption. It should then be verified (i) whether the enzymes are effectively present in the pollen of origin, and (ii) whether the bees have the enzymatic capacity to liberate the active cyanide and allyl isothiocyanate, and if so, at which level of activity. 
While we largely discussed the advantage of detecting specialized metabolites to avoid them, another evolutionary framework might also prevail from the pollinators' perspective: an active intake of specialized metabolites for medicinal purposes. Indeed, besides neutral or negative impact on bees, pollen specialized metabolites could also improve their health status through antioxidant and anti-microbial properties (e.g., Aličić et al., 2014; Palmer-Young et al., 2017). Such active intake of dietary chemicals suitable to improve health status corresponds to the concept of "self-medication" (Beaulieu and Schaefer, 2013), which occurs in many taxa (Povey et al., 2008; Forbey et al., 2009; Singer et al., 2009; Hart, 2011; Parker et al., 2011). While nutritional resilience to some environmental stressors has been already demonstrated in bees (e.g., heat waves, Vanderplanck et al., 2019a; parasites, Richardson et al., 2015; Vanderplanck et al., 2019b), there is only limited evidence for their ability to recognize and use specialized metabolites as medicinal resources when exposed to environmental stressors. There is then an urgent need to repeat similar experiments assessing the detection and effects of specialized metabolites in bees exposed to environmental stressors such as pesticides, diseases and parasites. Such experimental ecology could allow for developing operational research and proposing nature-based solutions in the current context of global bee declines.

\section{DATA AVAILABILITY STATEMENT}

The datasets presented in this study can be found in online repositories. The names of the repository/repositories and accession number(s) can be found below: Data Dryad, doi: 10.5061/dryad.2jm63xspz.

\section{REFERENCES}

Adler, L. S. (2000). The ecological significance of toxic nectar. Oikos 91, 409-420. doi: 10.1034/j.1600-0706.2000.910301.x

Alaux, C., Ducloz, F., Crauser, D., and Le Conte, Y. (2010). Diet effects on honeybee immunocompetence. Biol. Let. 6, 562-565. doi: 10.1098/rsbl.2009.0986

Aličić, D., Šubarić, D., Jašić, M., Pašalić, H., and Ačkar, Đ (2014). Antioxidant properties of pollen. Hrana u Zdravlju i Bolesti Znanstveno-struèni Ėasopis za Nutricionizam i Dijetetiku 3, 6-12.

Ares, A. M., Nozal, M. J., and Bernal, J. (2015). Development and validation of a liquid chromatography-tandem mass spectrometry method to determine intact glucosinolates in bee pollen. J. Chromatogr. B Analyt. Technol. Biomed. Life Sci. 1000, 49-56. doi: 10.1016/j.jchromb.2015.07.017

Arnold, S. E. J., Idrovo, M. E. P., Arias, L. J. L., Belmain, S. R., and Stevenson, P. C. (2014). Herbivore defence compounds occur in pollen and reduce bumblebee colony fitness. J. Chem. Ecol. 40, 878-881. doi: 10.1007/s10886-014-0467-4

Ayestaran, A., Giurfa, M., and de Brito Sanchez, M. G. (2010). Toxic but drank: gustatory aversive compounds induce post-ingestional malaise in harnessed honeybees. PLoS One 5:e15000. doi: 10.1371/journal.pone.0015000

Baracchi, D., Brown, M. F. J., and Chittka, L. (2015). Behavioural evidence for selfmedication in bumblebees? F1000 Res. 4:73. doi: 10.12688/f1000research.62 62.2

Beaulieu, M., and Schaefer, H. M. (2013). Rethinking the role of dietary antioxidants through the lens of self-medication. Anim. Behav. 86, 17-24. doi: 10.1016/j.anbehav.2013.05.022

Billiet, A., Meeus, I., Van Nieuwerburgh, F., Deforce, D., Wäckers, F., and Smagghe, G. (2015). Impact of sugar syrup and pollen diet on the bacterial diversity in the

\section{AUTHOR CONTRIBUTIONS}

MV conceptualized the project and led the experiments. OS, MG, and MV conducted the biological assays. OS, DN, PG, and PD collected, analyzed, and interpreted histological and chromatographic data. MV, AG, and MG conducted the statistical analyses data and wrote the manuscript. All authors reviewed and edited the manuscript.

\section{FUNDING}

Contributions from MV were supported by the ARC project "METAFLORE." MG was supported by the Swedish Research Council grant number 2018-06238. Open access publication costs were supported by the UMONS Research Institute for Biosciences.

\section{ACKNOWLEDGMENTS}

We would like to thank M. Bourguignon, E. Couture, M. Dehon, D. Evrard, H. Gilles, J. Kieffer, M. Poivre, N. Roger, and P.-L. Zerck for their assistance, as well as T. Wood (native speaker) for English proofreading. We gratefully acknowledge financial support from the UMONS Research Institute for Biosciences for open access publication charges.

\section{SUPPLEMENTARY MATERIAL}

The Supplementary Material for this article can be found online at: https://www.frontiersin.org/articles/10.3389/fevo.2021. 669352/full\#supplementary-material

gut of indoor-reared bumblebees (Bombus terrestris). Apidologie 47, 548-560. doi: 10.1007/s13592-015-0399-1

Bonilla-Rosso, G., and Engel, P. (2018). Functional roles and metabolic niches in the honey bee gut microbiota. Curr. Opin. Microbiol. 43, 69-76. doi: 10.1016/j. mib.2017.12.009

Boulogne, I., Petit, F., Ozier-Lafontaine, H., Desfontaines, L., and LorangerMerciris, G. (2012). Insecticidal and antifungal chemicals produced by plants: a review. Environ. Chem. Lett. 10, 325-347. doi: 10.1007/s10311-012-0359-1

Brochu, K. K., van Dyke, M. T., Milano, N. J., Petersen, J. D., McArt, S. H., Nault, B. A., et al. (2020). Pollen defenses negatively impact foraging and fitness in a generalist bee (Bombus impatiens: Apidae). Sci. Rep. 10:3112.

Brodschneider, R., and Crailsheim, K. (2010). Nutrition and health in honey bees. Apidologie 41, 278-294. doi: 10.1051/apido/2010012

Brown, C., and Keith, S. (1987). Chemistry at the Solanaceae/Ithomiinae Interface. Ann. Mo. Bot. Gard. 74, 359-397. doi: 10.2307/2399406

Burden, C. M., Morgan, M. O., Hladun, K. R., Amdam, G. V., Trumble, J. J., and Smith, B. H. (2019). Acute sublethal exposure to toxic heavy metals alters honey bee (Apis mellifera) feeding behavior. Sci. Rep. 9:4253.

Calatayud, P. A., and Rabhé, Y. (2013). "Chapitre 6. Le tube digestif des insects," in Interactions Insectes-Plantes, eds N. Sauvion, C. Paul-André, D. Thiéry, and F. Marion-Pol (Marseille: IRD).

Cane, J. H. (2016). Adult pollen diet essential for egg maturation by a solitary Osmia bee. J. Insect Physiol. 95, 105-109. doi: 10.1016/j.jinsphys.2016. 09.011

Cane, J. H., Dobson, H. E. M., and Boyer, B. (2016). Timing and size of daily pollen meals eaten by adult females of a solitary bee (Nomia melanderi) (Apiformes: Halictidae). Apidologie 48, 17-30. doi: 10.1007/s13592-016-0444-8 
Cane, J. H., and Sipes, S. (2006). "Characterizing floral specialization by bees: analytical methods and a revised lexicon for oligolecty," in Plant-Pollinator Interactions: from Specialization to Generalization, eds N. M. Waser and J. Ollerton (Chicago, IL: The University of Chicago Press), 99-112.

Chowański, S., Adamski, Z., Marciniak, P., Rosiński, G., Büyükgüzel, E., Büyükgüzel, K., et al. (2016). A Review of bioinsecticidal activity of Solanaceae alkaloids. Toxins 8:60. doi: 10.3390/toxins8030060

Compean, K. L., and Ynalvez, R. A. (2014). Antimicrobial activity of plant secondary metabolites: a review. Res. J. Med. Plant 8, 204-213. doi: 10.3923/ rjmp.2014.204.213

Conn, E. E. (1978). "Cyanogenesis, the production of hydrogen cyanide, by plants," in Effects of Poisonous Plants on Livestock, eds R. F. Keeler, K. R. Van kampen, and L. F. James (New York, NY: Academic Press), 301-310. doi: 10.1016/b9780-12-403250-7.50035-2

Cook, D., Manson, J. S., Gardner, D. R., Welch, K. D., and Irwin, R. E. (2013). Norditerpene alkaloid concentrations in tissues and floral rewards of larkspurs and impacts on pollinators. Biochem. Syst. Ecol. 48, 123-131. doi: 10.1016/j.bse. 2012.11.015

Dag, A., Zipori, I., and Pleser, Y. (2006). Using bumblebees to improve almond pollination by the honeybee. J. Apic. Res. 45, 215-216. doi: 10.3896/ibra.1.45.4.08

Day, S., Beyer, R., Mercer, A., and Ogden, S. (1990). The nutrient composition of honeybee collected pollen in Otago. N. Z. J. Apic. Res. 29, 138-146. doi: 10.1080/00218839.1990.11101210

de Brito Sanchez, M. G. (2011). Taste perception in honey bees. Chem. Senses 36, 675-692. doi: 10.1093/chemse/bjr040

de Carvalho, A. C. P., and Message, D. (2004). A scientific note on the toxic pollen of Stryphnodendron polyphyllum (Fabaceae, Mimosoideae) which causes sacbrood-like symptoms. Apidologie 35, 89-90. doi: 10.1051/apido:2003059

de Roode, J. C., Lefèvre, T., and Hunter, M. D. (2013). Ecology. Self-medication in animals. Science 340, 150-151. doi: 10.1126/science.1235824

DeGrandi-Hoffman, G., Chen, Y., Huang, E., and Huang, M. H. (2010). The effect of diet on protein concentration, hypopharyngeal gland development and virus load in worker honey bees (Apis mellifera L.). J. Insect Physiol. 56, 1184-1191. doi: 10.1016/j.jinsphys.2010.03.017

Detzel, A., and Wink, M. (1993). Attraction, deterrence or intoxication of bees (Apis mellifera) by plant allelochemicals. Chemoecology 4, 8-18. doi: 10.1007/ bf01245891

Di Pasquale, G., Salignon, M., Le Conte, Y., Belzunces, L. P., Decourtye, A., Kretzschmar, A., et al. (2013). Influence of pollen nutrition on honey bee health: do pollen quality and diversity matter? PLoS One 8:e72016. doi: 10.1371/journal. pone.0072016

Dicks, L., Breeze, T., Ngo, H., Senapathi, D., An, J., Aizen, M., et al. (2020). A global assessment of drivers and risks associated with pollinator decline. Res. Sq. doi: 10.21203/rs.3.rs- $90439 /$ v1

Dobson, H. E. M., and Bergström, G. (2000). The ecology and evolution of pollen odors. Plant Syst. Evol. 222, 63-87. doi: 10.1007/978-3-7091-6306-1_4

Dobson, H. E. M., and Peng, Y. S. (1997). Digestion of pollen components by larvae of the flower- specialist bee Chelostoma florisomne (Hymenoptera: Megachilidae). J. Insect Physiol. 43, 89-100. doi: 10.1016/s0022-1910(96) 00024-8

Dolezal, A. G., Carrillo-Tripp, J., Judd, T. M., Miller, W. A., Bonning, B. C., and Toth, A. L. (2019). Interacting stressors matter: diet quality and virus infection in honeybee health. R. Soc. Open Sci. 6:181803. doi: 10.1098/rsos.181803

Eckhardt, M., Haider, M., Dorn, S., and Müller, A. (2014). Pollen mixing in pollen generalist solitary bees: a possible strategy to complement or mitigate unfavourable pollen properties? J. Anim. Ecol. 83, 588-597. doi: 10.1111/13652656.12168

Engel, P., and Moran, N. A. (2013). The gut microbiota of insects-diversity in structure and function. FEMS Microbiol. Rev. 37, 699-735. doi: 10.1111/15746976.12025

Erickson, M., and Feeny, P. (1974). Sinigrin: a chemical barrier to the black swallowtail butterfly, Papilio polyxenes. Ecology 55, 103-111. doi: 10.2307/ 1934622

Feldhaar, H. (2011). Bacterial symbionts as mediators of ecologically important traits of insects hosts. Ecol. Entomol. 36, 533-543. doi: 10.1111/j.1365-2311. 2011.01318.x

Forbey, J. S., Harvey, A. L., Huffman, M. A., Provenza, F. D., Sullivan, R., and Tasdemir, D. (2009). Exploitation of secondary metabolites by animals: a response to homeostatic challenge. Integr. Comp. Biol. 49, 314-328. doi: 10.1093/icb/icp046
Fraenkel, G. S. (1959). The raison d'être of secondary plant substances. Science 129, 1466-1470. doi: 10.1126/science.129.3361.1466

Free, J. B. (1993). Insect Pollination of Crops, 2nd Edn. London: Academic Press, 768.

French, A. S., Sellier, M. J., Ali Agha, M., Guigue, A., Chabaud, M. A., Reeb, P. D., et al. (2015). Dual mechanism for bitter avoidance in Drosophila. J. Neurosci. 35, 3990-4004. doi: 10.1523/jneurosci.1312-14.2015

Frisch, T., Motawia, M. S., Olsen, C. E., Agerbirk, N., Møller, B. L., and Bjarnholt, N. (2015). Diversified glucosinolate metabolism: biosynthesis of hydrogen cyanide and of the hydroxynitrile glucoside alliarinoside in relation to sinigrin metabolism in Alliaria petiolata. Front. Plant Sci. 6:926. doi: 10.3389/fpls.2015. 00926

Gauthier, M., Cano-Lozano, V., Zaoujal, A., and Richard, D. (1994). Effects of intracranial injections of scopolamine on olfactory conditioning retrieval in the honeybee. Behav. Brain Res. 63, 145-149. doi: 10.1016/0166-4328(94)90085-x

Génissel, A., Aupinel, P., Bressac, C., Tasei, J. N., and Chevrier, C. (2002). Influence of pollen origin on performance of Bombus terrestris microcolonies. Entomol. Exp. Appl. 104, 329-336. doi: 10.1046/j.1570-7458.2002.01019.x

Gibson-Corley, K. N., Olivier, A. K., and Meyerholz, D. K. (2013). Principles for valid histopathologic scoring in research. Vet. Pathol. 50, 1007-1015. doi: 10.1177/0300985813485099

Gosselin, M., Michez, D., Vanderplanck, M., Roelants, D., Glauser, G., and Rasmont, P. (2013). Does Aconitum septentrionale chemically protect floral rewards to the advantage of specialist bumblebees? Ecol. Entomol. 38, 400-407. doi: 10.1111/een.12032

Goulson, D., Nicholls, E., Botias, C., and Rotheray, E. L. (2015). Bee declines driven by combined stress from parasites, pesticides, and lack of flowers. Science 347:1255957. doi: 10.1126/science.1255957

Haider, M., Dorn, S., and Müler, A. (2013). Intra- and interpopulational variation in the ability of a solitary bee species to develop on non-host-pollen: implications for host range expansion. Funct. Ecol. 27, 255-263. doi: 10.1111/1365-2435. 12021

Hanley, M. E., Franco, M., Pichon, S., Darvill, B., and Goulson, D. (2008). Breeding system, pollinator choice and variation in pollen quality in British herbaceous plants. Funct. Ecol. 22, 592-598. doi: 10.1111/j.1365-2435.2008.01415.x

Harrison, X. A. (2014). Using observation-level random effects to model overdispersion in count data in ecology and evolution. PeerJ 2:e616. doi: $10.7717 /$ peerj.616

Hart, B. L. (2011). Behavioural defences in animals against pathogens and parasites: parallels with the pillars of medicine in humans. Philos. Trans. R. Soc. Lond. B Biol. Sci. 366, 3406-3417. doi: 10.1098/rstb.2011.0092

Herbert, E. W. (1992). "Honey bee nutrition," in The Hive and the Honeybee, ed. J. M. Graham (Hamilton, IL: Dadant), 197-233.

Hothorn, T., Bretz, F., and Westfall, P. (2008). Simultaneous inference in general parametric models. Biom. J. 50, 346-363. doi: 10.1002/bimj.200810425

Human, H., Nicolson, S. W., Strauss, K., Pirk, C. W. W., and Dietemann, V. (2007). Influence of pollen quality on ovarian development in honeybee workers (Apis mellifera scutellata). J. Insect Physiol. 53, 649-655. doi: 10.1016/j.jinsphys.2007. 04.002

Humphrey, P. T., Gloss, A. D., Alexandre, N. M., Villalobos, M. M., Fremgen, M. R., Groen, S. C., et al. (2016). Aversion and attraction to harmful plant secondary compounds jointly shape the foraging ecology of a specialist herbivore. Ecol. Evol. 6, 3256-3268. doi: 10.1002/ece3.2082

Hurst, V., Stevenson, P. C., and Wright, G. A. (2014). Toxins induce 'malaise' behaviour in the honeybee (Apis mellifera). J. Comp. Physiol. A. 200, 881-890. doi: 10.1007/s00359-014-0932-0

Hügel, M. F. (1962). Etude de quelques constituants du pollen. Ann. l'Abeille 5, 97-133. doi: 10.1051/apido:19620201

Ismail, N., Christine, S., Robinson, G. E., and Fahrbach, S. E. (2008). Pilocarpine improves recognition of nestmates in young honey bees. Neurosci. Lett. 439, 178-181. doi: 10.1016/j.neulet.2008.05.014

Janashia, I., and Alaux, C. (2016). Specific immune stimulation by endogenous bacteria in honey bees (Hymenoptera: Apidae). J. Econ. Entomol. 109, 14741477. doi: $10.1093 /$ jee/tow065

Kempf, M., Heil, S., Haßlauer, I., Schmidt, L., von der Ohe, K., Theuring, C., et al. (2010). Pyrrolizidine alkaloids in pollen and pollen products. Mol. Nutr. Food Res. 54, 292-300. doi: 10.1002/mnfr.200900289

Kešnerová, L., Mars, R. A. T., Ellegaard, K. M., Troilo, M., Sauer, U., and Engel, P. (2017). Disentangling metabolic functions of bacteria in the honey bee gut. PLoS Biol. 15:e2003467. doi: 10.1371/journal.pbio.2003467 
Kevan, P. G., and Ebert, T. (2005). Can almond nectar and pollen poison honey bees? Am. Bee J. 145, 507-509.

King, M. J. (1993). Buzz foraging mechanism in bumble bees. J. Apic. Res. 32, 41-49. doi: $10.1080 / 00218839.1993 .11101286$

Kitaoka, T. K., and Nieh, J. C. (2009). Bumble bee pollen foraging regulation: role of pollen quality, storage levels, and odor. Behav. Ecol. Sociobiol. 63, 501-510. doi: 10.1007/s00265-008-0684-3

Kissen, R., Rossiter, J. T., and Bones, A. M. (2009). The "Mustard Oil Bomb": not so easy to assemble?! localization, expression and distribution of the components of the myrosinase enzyme system. Phytochem. Rev. 8, 69-86. doi: 10.1007/ s11101-008-9109-1

Kleijn, D., and Raemakers, I. (2008). A retrospective analysis of pollen host plant use by stable and declining bumble bee species. Ecology 89, 1811-1823. doi: 10.1890/07-1275.1

Kolassa, J. E., and Jankowski, S. (2021). MultNonParam: Mutlivariate Nonparametric Methods. $R$ package Version 1.3.5. Available online at: https://cran.r-project.org/package=MultNonParam. (Accessed June 3, 2021).

Kuznetsova, A., Brockhoff, P. B., and Christensen, R. H. B. (2017). lmerTest package: tests in linear mixed effects models. J. Stat. Softw. 82, 1-26.

Leonhardt, S. D., and Blüthgen, N. (2012). The same, but different: pollen foraging in honeybee and bumblebee colonies. Apidologie 43, 449-464. doi: 10.1007/ s13592-011-0112-y

Levin, M. D., and Haydak, M. H. (1957). Comparative value of different pollens in the nutrition of Osmia lignaria Say (Hymenoptera: Apoidea). Bee World 38, 221-226. doi: 10.1080/0005772x.1957.11095007

London-Shafir, I., Shafir, S., and Eisikowitch, D. (2003). Amygdalin in almond nectar and pollen-facts and possible roles. Plant Syst. Evol. 238, 87-95. doi: 10.1007/s00606-003-0272-y

Lunau, K. (2000). The ecology and evolution of visual pollen signals. Plant Syst. Evol. 222, 89-111. doi: 10.1007/978-3-7091-6306-1_5

Lunau, K., Piorek, V., Krohn, O., and Pacini, E. (2015). Just spines-mechanical defense of malvaceous pollen against collection by corbiculate bees. Apidologie 46, 144-149. doi: 10.1007/s13592-014-0310-5

Ma, C., Kessler, S., Simpson, A., and Wright, G. A. (2016). Novel behavioral assay to investigate gustatory responses of individual, freely-moving bumble bees (Bombus terrestris). J. Vis. Exp. 113:54233.

Manson, J. S., Otterstatter, M. C., and Thomson, J. D. (2010). Consumption of a nectar alkaloid reduces pathogen load in bumble bees. Oecologia 162, 81-89. doi: 10.1007/s00442-009-1431-9

Marqués, A., Juan, A., Ruíz, M., Traveset, A., and Leza, M. (2019). Improvement of almond production using Bombus terrestris (Hymenoptera: Apidae) in Mediterranean conditions. J. Appl. Entomol. 143, 1132-1142. doi: 10.1111/jen. 12690

Mazumder, A., Dwivedi, A., and du Plessis, J. (2016). Sinigrin and its therapeutic benefits. Molecules 21:416. doi: 10.3390/molecules21040416

Mendiburu, F. (2020). Agricolae: Statistical Procedures for Agricultural Research. $R$ Package Version 1.3-3. Available online at: http://CRAN.R-project.org/ package $=$ agricolae. $($ Accessed June 6, 2021)

Moerman, R., Vanderplanck, M., Fournier, D., Jacquemart, A.-L., and Michez, D. (2017). Pollen nutrients better explain bumblebee colony development than pollen diversity. Insect Conserv. Divers. 10, 171-179. doi: 10.1111/icad.12213

Mommaerts, V., Wackers, F., and Smagghe, G. (2013). Assessment of gustatory responses to different sugars in harnessed and free-moving bumblebee workers (Bombus terrestris). Chem. Senses 38, 399-407. doi: 10.1093/chemse/bjt014

Moore, B. D., Andrew, R. L., Külheim, C., and Foley, W. J. (2014). Explaining intraspecific diversity in plant secondary metabolites in an ecological context. New Phytol. 201, 733-750. doi: 10.1111/nph.12526

Moret, Y., and Schmid-Hempel, P. (2000). Survival for immunity: the price of immune system activation for bumblebee workers. Science 290, 1166-1168. doi: $10.1126 /$ science. 290.5494 .1166

Müller, A. (1996). Convergent evolution of morphogical specializations in Central European bee and honey wasp species as an adaptation to the uptake of pollen from nototribic flowers (Hymenoptera, Apoidea and Masaridae). Biol. J. Linn. Soc. 57, 235-252. doi: 10.1006/bijl.1996.0013

Muth, F., Francis, J. S., and Leonard, A. S. (2016). Bees use the taste of pollen to determine which flowers to visit. Biol. Lett. 12:20160356. doi: 10.1098/rsbl.2016. 0356

Nayar, J. K., and Thorsteinson, A. J. (1963). Further investigations into the chemical basis of insect-host plant relationships in an oligophagous insect, Plutella maculipennis (Curtis) (Lepidoptera: Plutellidae). Can. J. Zool. 41, 923-929. doi: 10.1139/z63-066

Palmer-Young, E. C., Farrell, I. W., Adler, L. S., Milano, N. J., Egan, P., Juncker, R., et al. (2019). Chemistry of floral rewards: intra- and interspecific variability of nectar and pollen secondary metabolites across taxa. Ecol. Monogr. 89:e01335.

Palmer-Young, E. C., Tozkar, C. O., Schwarz, R. S., Chen, Y., Irwin, R. E., Adler, L. S., et al. (2017). Nectar and pollen phytochemicals stimulate honey bee (Hymenoptera: Apidae) immunity to viral infection. J. Econ. Entomol. 110, 1959-1972. doi: 10.1093/jee/tox193

Paris, L., Peghaire, E., Moné, A., Diogon, M., Debroas, D., Delbac, F., et al. (2020). Honeybee gut microbiota dysbiosis in pesticide/parasite co-exposures is mainly induced by Nosema ceranae. J. Invertebr. Pathol. 172:107348. doi: 10.1016/j.jip. 2020.107348

Parker, B. J., Barribeau, S. M., Laughton, A. M., de Roode, J. C., and Gerardo, N. M. (2011). Non-immunological defense in an evolutionary framework. Trends Ecol. Evol. 26, 242-248. doi: 10.1016/j.tree.2011.02.005

Pernal, S., and Currie, R. (2002). Discrimination and preferences for pollen-based cues by foraging honeybees, Apis mellifera L. Anim. Behav. 63, 369-390. doi: 10.1006/anbe.2001.1904

Potts, S. G., Imperatriz-Fonseca, V., Ngo, H., Aizen, M., Biesmeijer, J., Breeze, T. et al. (2016). Safeguarding pollinators and their values to human well-being. Nature 540, 220-229. doi: 10.1038/nature20588

Povey, S., Cotter, S. C., Simpson, S. J., Lee, K. P., and Wilson, K. (2008). Can the protein costs of bacterial resistance be offset by altered feeding behaviour? J. Anim. Ecol. 78, 437-446. doi: 10.1111/j.1365-2656.2008.01499.x

Praz, C. J., Müller, A., and Dorn, S. (2008a). Host recognition in a pollen-specialist bee: evidence for a genetic basis. Apidologie 39, 547-557. doi: 10.1051/apido: 2008034

Praz, C. J., Müller, A., and Dorn, S. (2008b). Specialized bees fail to develop on non-host pollen: do plants chemically protect their pollen? Ecology 89, 795-804. doi: 10.1890/07-0751.1

Quezada-Euan, J. J. G., Lopez-Velasco, A., Perez-Balam, J., Moo-Valle, H., Velazquez-Madrazo, A., and Paxton, R. J. (2011). Body size differs in workers produced across time and is associated with variation in the quantity and composition of larval food in Nannotrigona perilampoides (Hymenoptera. Meliponini). Insectes Soc. 58, 31-38. doi: 10.1007/s00040-010-0113-2

R Core Team (2017). R: a Language and Environment for Statistical Computing. Vienna: R Foundation for Statistical Computing.

Rasheed, S. A., and Harder, L. D. (1997). Economic motivation for plant species preferences of pollen-collecting bumble bees. Econ. Entomol. 2, 209-219. doi: 10.1046/j.1365-2311.1997.t01-1-00059.x

Rasmont, P., Coppée, A., Michez, D., and De Meulemeester, T. (2008). An overview of the Bombus terrestris (L. 1758) subspecies (Hymenoptera: Apidae). Ann. Soc. Entomol. Fr. 44, 243-250. doi: 10.1080/00379271.2008.10697559

Rasmont, P., Regali, A., Ings, T. C., Lognay, G., Baudart, E., Marlier, M., et al. (2005). Analysis of pollen and nectar of Arbutus unedo as a food source for Bombus terrestris (Hymenoptera: Apidae). J. Econ. Entomol. 98, 656-663.

Reilly, S., and Schachtman, R. (2009). Conditioned Taste Aversion: Behavioral and Neural Processes. Oxford: Oxford University Press.

Richards, L. A., Dyer, L. A., Forister, M. L., Smilanich, A. M., Dodson, C. D., Leonard, M. D., et al. (2015). Phytochemical diversity drives plant-insect community diversity. Proc. Natl. Acad. Sci. U.S.A. 112, 10973-10978. doi: 10.1073/pnas. 1504977112

Richardson, L. L., Adler, L. S., Leonard, A. S., Andicoechea, J., Regan, K. H., Anthony, W. E., et al. (2015). Secondary metabolites in floral nectar reduce parasite infections in bumblebees. Proc. R. Soc. B 282:20142471. doi: 10.1098/ rspb.2014.2471

Ricketts, T. H., Regetz, J., Steffan-Dewenter, I., Cunningham, S. A., Kremen, C., Bogdanski, A., et al. (2008). Landscape effects on crop pollination services: are there general patterns? Ecol. Lett. 11, 499-515. doi: 10.1111/j.1461-0248.2008. 01157.x

Rivest, S., and Forrest, J. R. K. (2020). Defence compounds in pollen: why do they occur and how do they affect the ecology and evolution of bees? New Phytol. 225, 1053-1064. doi: 10.1111/nph.16230

Robertson, A. W., Mountjoy, C., Faulkner, B. E., Roberts, M. V., and Macnair, M. R. (1999). Bumblebee selection of Mimulus guttatus flowers: the effects of pollen quality and reward depletion. Ecology 80, 2594-2606. doi: 10.2307/177243

Robinson, M. E. (1930). Cyanogenesis in plants. Biol. Rev. 5, 126-141. doi: 10.1111/ j.1469-185x.1930.tb00896.x 
Roger, N., Michez, D., Wattiez, R., Sheridan, C., and Vanderplanck, M. (2017). Diet effects on bumblebee health. J. Insect Physiol. 96, 128-133. doi: 10.1016/j. jinsphys.2016.11.002

Roulston, T. H., and Cane, J. H. (2000). Pollen nutritional content and digestibility for animals. Plant Syst. Evol. 222, 187-209. doi: 10.1007/978-3-7091-6306-1_10

Roulston, T. H., Cane, J. H., and Buschmann, S. L. (2000). What governs protein content of pollen: pollinator preferences, pollen-pistil interactions, or phylogeny? Ecol. Monogr. 70, 617-643. doi: 10.2307/2657188

Ruedenauer, F. A., Raubenheimer, D., Kessner-Beierlen, D., Grund-Muller, N., Noack, L., Spaethe, J., et al. (2020a). Best be(e) on low fat: linking nutrient perception, regulation and fitness. Ecol. Lett. 23, 545-554. doi: 10.1111/ele. 13454

Ruedenauer, F. A., Spaethe, J., and Leonhardt, S. D. (2015). How to know which food is good for you: bumblebees use taste to discriminate between different concentrations of food differing in nutrient content. J. Exp. Biol. 218, 22332240. doi: $10.1242 / \mathrm{jeb} .118554$

Ruedenauer, F. A., Spaethe, J., and Leonhardt, S. D. (2016). Hungry for qualityindividual bumblebees forage flexibly to collect high-quality pollen. Behav. Ecol. Sociobiol. 70, 1209-1217. doi: 10.1007/s00265-016-2129-8

Ruedenauer, F. A., Sydow, D., Spaethe, J., and Leonhardt, S. D. (2020b). Young bumblebees may rely on both direct pollen cues and early experience when foraging. Proc. R. Soc. B 287:20201615. doi: 10.1098/rspb.2020.1615

Sáez, A., Aizen, M. A., Medici, S., Viel, M., Villalobos, E., and Negri, P. (2020). Bees increase crop yield in an alleged pollinator-independent almond variety. Sci. Rep. 10:3177.

Sarwade, A. B., and Bhawane, G. P. (2013). Anatomical and histological structure of digestive tract of adult Platynotus belli (Coleoptera: Tenebrionidae). Biol. Forum Int. J. 5, 47-55.

Sedivy, C., Müller, A., and Dorn, S. (2011). Closely related pollen generalist bees differ in their ability to develop on the same pollen diet: evidence for physiological adaptations to digest pollen. Funct. Ecol. 25, 718-725. doi: 10. $1111 / j .1365-2435.2010 .01828 . x$

Shields, V. D. C., and Mitchell, B. K. (1995). Sinigrin as a feeding deterrent in two crucifer-feeding, polyphagous lepidopterous species and the effects of feeding stimulant mixtures on deterrency. Philos. Trans. R. Soc. Lond. B 347, 439-446. doi: 10.1098/rstb.1995.0035

Singaravelan, N., Ne'eman, G., Inbar, M., and Izhaki, I. (2005). Feeding responses of free-flying honeybees to secondary compounds mimicking floral nectars. J. Chem. Ecol. 31, 2791-2804. doi: 10.1007/s10886-005-8394-z

Singer, M. S., Mace, K. C., and Bernays, E. A. (2009). Self-medication as adaptative plasticity: increased ingestion of plant toxins by parasitized caterpillars. PLoS One 4:e4796. doi: 10.1371/journal.pone.0004796

Stegemann, T., Kruse, L. H., Brütt, M., and Ober, D. (2018). Specific distribution of pyrrolizidine alkaloids in floral parts of comfrey (Symphytum officinale) and its implications for flower ecology. J. Chem. Ecol. 45, 128-135. doi: 10.1007/ s10886-018-0990-9

Stevenson, P. C. (2020). For antagonists and mutualists: the paradox of insect toxic secondary metabolites in nectar and pollen. Phytochem. Rev. 19, 603-614. doi: 10.1007/s11101-019-09642-y

Stevenson, P. C., Nicolson, S. W., and Wright, G. A. (2017). Plant secondary metabolites in nectar: impacts on pollinators and ecological functions. Funct. Ecol. 31, 65-75. doi: 10.1111/1365-2435.12761

Tasei, J. N., and Aupinel, P. (2008a). Nutritive value of 15 single pollens and pollen mixes tested on larvae produced by bumble bee workers (Bombus terrestris, Hymenoptera: Apidae). Apidologie 39, 397-409. doi: 10.1051/apido:2008017

Tasei, J. N., and Aupinel, P. (2008b). Validation of a method using queenless Bombus terrestris micro-colonies for testing the nutritive value of commercial pollen mixes by comparison with queenright colonies. J. Econ. Entomol. 101, 1737-1742. doi: 10.1603/0022-0493-101.6.1737

Thomson, J. D., and Thomson, B. A. (1992). "Pollen presentation and viability schedules in animal-pollinated plants: consequences for reproductive success," in Ecology and Evolution of Plant Reproduction: New Approaches, ed. R. Wyatt (New York, NY: Chapman \& Hall), 1-24.

Tiedeken, E. J., Stout, J. C., Stevenson, P. C., and Wright, G. A. (2014). Bumblebees are not deterred by ecologically relevant concentrations of nectar toxins. J. Exp. Biol. 217, 1620-1625.

Trunz, V., Lucchetti, M. A., Bénon, D., Dorchin, A., Desurmont, G. A., Kast, C., et al. (2020). To bee or not to bee: the 'raison d'être' of toxic secondary compounds in the pollen of Boraginaceae. Funct. Ecol. 34, 1345-1357. doi: $10.1111 / 1365-2435.13581$
Vanderplanck, M., Declèves, S., Roger, N., Decroo, C., Caulier, G., Glauser, G., et al. (2018). Is non-host pollen suitable for generalist bumblebees? Insect Sci. 25, 259-272. doi: 10.1111/1744-7917.12410

Vanderplanck, M., Gilles, H., Nonclercq, D., Duez, P., and Gerbaux, P. (2020). Asteraceae paradox: chemical and mechanical protection of Taraxacum pollen. Insects 11:304. doi: 10.3390/insects11050304

Vanderplanck, M., Martinet, B., Carvalheiro, L. G., Rasmont, P., Barraud, A., Renaudeau, C., et al. (2019a). Ensuring access to high-quality resources reduces the impacts of heat stress on bees. Sci. Rep. 9:12596.

Vanderplanck, M., Moerman, R., Rasmont, P., Lognay, G., Wathelet, B., Wattiez, R., et al. (2014). How does pollen chemistry impact development and feeding behaviour of polylectic bees? PLoS One 9:e86209. doi: 10.1371/journal.pone. 0086209

Vanderplanck, M., Roger, N., Moerman, R., Ghisbain, G., Gérard, M., Popowski, D., et al. (2019b). Bumble bee parasite prevalence but not genetic diversity impacted by the invasive plant Impatiens glandulifera. Ecosphere 10:e02804.

Vaudo, A. D., Patch, H. M., Mortensen, D. A., Tooker, J. F., and Grozinger, C. M. (2016a). Macronutrient ratios in pollen shape bumble bee (Bombus impatiens) foraging strategies and floral preferences. Proc. Natl. Acad. Sci. U.S.A. 113, E4035-E4042.

Vaudo, A. D., Stabler, D., Patch, H. M., Tooker, J. F., Grozinger, C. M., and Wright, G. A. (2016b). Bumble bees regulate their intake of essential protein and lipid pollen macronutrients. J. Exp. Biol. 219, 3962-3970.

Vaudo, A. D., Tooker, J. F., Grozinger, C. M., and Patch, H. M. (2015). Bee nutrition and floral resource restoration. Curr. Opin. Insect Sci. 10, 133-141. doi: 10.1016/j.cois.2015.05.008

Vaudo, A. D., Tooker, J. F., Patch, H. M., Biddinger, D. J., Coccia, M., Crone, M. K., et al. (2020). Pollen protein:lipid macronutrient ratios may guide broad patterns of bee species floral preferences. Insects 11:132. doi: 10.3390/insects110 20132

Velthuis, H. H. W., and van Doorn, A. (2006). A century of advances in bumblebee domestication and the economic and environmental aspect of its commercialization for pollination. Apidologie 37, 421-451. doi: 10.1051/apido: 2006019

Weiner, C. N., Hilpert, A., Werner, M., Linsenmair, K. E., and Bluthgen, N. (2010). Pollen amino acids and flower specialisation in solitary bees. Apidologie 41, 476-487. doi: 10.1051/apido/2009083

Westerkamp, C., and Claben-Bockhoff, R. (2007). Bilabiate flowers: the ultimate response to bees? Ann. Bot. 100, 361-374. doi: 10.1093/aob/mcm123

Winfree, R., Aguilar, R., Vasquez, D. P., LeBuhn, G., and Aizen, M. A. (2009). A meta-analyis of bees'responses to anthropogenic disturbance. Ecology 90 , 2068-2076. doi: 10.1890/08-1245.1

Wink, M. (1993). "Allelochemical properties or the raison d'être of Alkaloids," in The Alkaloids, Vol. 43, ed. J. Cordell (New York, NY: Academic Press), 1-118. doi: 10.1016/s0099-9598(08)60134-0

Wright, G. A., Baker, D. D., Palmer, M. J., Stabler, D., Mustard, J. A., Power, E. F., et al. (2013). Caffeine in floral nectar enhances a pollinator's memory of reward. Science 339, 1202-1204. doi: 10.1126/science. 1228806

Wright, G. A., Mustard, J. A., Simcock, N. K., Ross-Taylor, A. A., McNicholas, L. D., Popescu, A., et al. (2010). Parallel reinforcement pathways for conditioned food aversions in the honeybee. Curr. Biol. 20, 2234-2240. doi: 10.1016/j.cub.2010. 11.040

Conflict of Interest: The authors declare that the research was conducted in the absence of any commercial or financial relationships that could be construed as a potential conflict of interest.

Publisher's Note: All claims expressed in this article are solely those of the authors and do not necessarily represent those of their affiliated organizations, or those of the publisher, the editors and the reviewers. Any product that may be evaluated in this article, or claim that may be made by its manufacturer, is not guaranteed or endorsed by the publisher.

Copyright (c) 2021 Sculfort, Gérard, Gekière, Nonclercq, Gerbaux, Duez and Vanderplanck. This is an open-access article distributed under the terms of the Creative Commons Attribution License (CC BY). The use, distribution or reproduction in other forums is permitted, provided the original author(s) and the copyright owner(s) are credited and that the original publication in this journal is cited, in accordance with accepted academic practice. No use, distribution or reproduction is permitted which does not comply with these terms. 